\title{
Multicriteria Decision Analysis and Group Decision-Making to Select Stand-Level Forest Management Models and Support Landscape-Level Collaborative Planning
}

\author{
Marlene Marques ${ }^{1, *(\mathbb{D})}$, Keith M. Reynolds ${ }^{2}{ }^{(}$, Marco Marto ${ }^{1}{ }^{(}$, Milena Lakicevic ${ }^{3}$, Carlos Caldas ${ }^{1}$, \\ Philip J. Murphy ${ }^{4}$ and José G. Borges ${ }^{1}$ (D) \\ 1 Forest Research Center, School of Agriculture, University of Lisbon, Tapada da Ajuda, \\ 1349-017 Lisboa, Portugal; marcovmarto@isa.ulisboa.pt (M.M.); carloscaldas@isa.ulisboa.pt (C.C.); \\ joseborges@isa.ulisboa.pt (J.G.B.) \\ 2 Corvallis Forestry Sciences Laboratory, Pacific Northwest Research Station, US Department of Agriculture, \\ Forest Service, 3200 SW Jefferson Way, Corvallis, OR 97331, USA; kreynolds@fs.fed.us \\ 3 Department of Fruit Science, Viticulture, Horticulture and Landscape Architecture, University of Novi Sad, \\ Faculty of Agriculture, Trg Dositeja Obradovića 8, 21000 Novi Sad, Serbia; milenal@polj.uns.ac.rs \\ 4 InfoHarvest, Inc., Seattle, WA 98165, USA; philip.murphy@infoharvest.com \\ * Correspondence: marlenegm@isa.ulisboa.pt
}

\section{check for} updates

Citation: Marques, M.; Reynolds, K.M.; Marto, M.; Lakicevic, M.; Caldas, C.; Murphy, P.J.; Borges, J.G. Multicriteria Decision Analysis and Group Decision-Making to Select Stand-Level Forest Management Models and Support Landscape-Level Collaborative Planning. Forests 2021, 12, 399. https://doi.org/10.3390/f12040399

Academic Editor: Isabella De Meo

Received: 6 March 2021

Accepted: 25 March 2021

Published: 28 March 2021

Publisher's Note: MDPI stays neutral with regard to jurisdictional claims in published maps and institutional affiliations.

Copyright: (c) 2021 by the authors. Licensee MDPI, Basel, Switzerland. This article is an open access article distributed under the terms and conditions of the Creative Commons Attribution (CC BY) license (https:// creativecommons.org/licenses/by/ $4.0 /)$.

\begin{abstract}
Forest management planning is a challenge due to the diverse criteria that need to be considered in the underlying decision-making process. This challenge becomes more complex in joint collaborative management areas (ZIF) because the decision now may involve numerous actors with diverse interests, preferences, and goals. In this research, we present an approach to identifying and quantifying the most relevant criteria that actors consider in a forest management planning process in a ZIF context, including quantifying the performance of seven alternative stand-level forest management models (FMM). Specifically, we developed a combined multicriteria decision analysis and group decision-making process by (a) building a cognitive map with the actors to identify the criteria and sub-criteria; (b) structuring the decision tree; (c) structuring a questionnaire to elicit the importance of criteria and sub-criteria in a pairwise comparison process, and to evaluate the FMM alternatives; and (d) applying a Delphi survey to gather actors' preferences. We report results from an application to a case study area, ZIF of Vale do Sousa, in North-Western Portugal. Actors assigned the highest importance to the criteria income (56.8\% of all actors) and risks (21.6\% of all actors) and the lowest to cultural services (27.0\% of all actors). Actors agreed on their preferences for the sub-criteria of income (diversification of income sources), risks (wildfires) and cultural services (leisure and recreation activities). However, there was a poor agreement among actors on the subcriteria of the wood demand and biodiversity criteria. For $27.0 \%$ of all actors the FMM with the highest performance was the pedunculate oak and for $43.2 \%$ of all actors the eucalypt FMM was the least preferable alternative. The findings indicate that this approach can support ZIF managers in enhancing forest management planning by improving its utility for actors and facilitating its implementation.
\end{abstract}

Keywords: forest management planning; ecosystem services; cognitive mapping; AHP; SMART; Delphi; participatory planning

\section{Introduction}

Contemporary planning for sustainable management of forest resources is a very complex problem, mainly due to the multiplicity of wide-ranging criteria involved in the underlying decision-making process (e.g., income, soil erosion, wildfire risk) (e.g., [1-3]). Forest management also needs to consider additional challenges such as climate change, dynamics of global markets, and societal demand. Practically, all such decision problems are inherently multicriteria in nature $[1,4]$. Joint collaborative forest management, e.g., ZIF 
(the acronym for Zona de Intervenção Florestal in Portuguese) is complicated further by the need to consider the diverse perspectives of numerous actors (e.g., forest owners, forest managers, public administration, market agents, and civil society) who bring different interests, concerns, preferences, values, and goals to the decision problem [5,6]. Thus, traditional decision-making approaches to stand-level forest management in North-Western Portugal with a primary focus on economics are unlikely to ensure the sustained provisioning of desired ecosystem services (ES) [7,8]. Innovative methods are needed for forest management decision-making in ZIF.

This innovation may encompass the use of multicriteria decision analysis (MCDA) methods. Belton and Stewart ([4], p. 2) define MCDA as "an umbrella term to describe a collection of formal approaches which seek to take explicit account of multiple criteria in helping individuals or groups explore decisions that matter." They involve several approaches that aim to support the systematic evaluation of alternatives with multiple, and often conflicting, objectives [4,9-11], thus helping actors and other decision-makers organize and synthesize complex information to facilitate confident decision-making [4], while accounting for diverse criteria. MCDA supports the evaluation and prioritization of alternatives that best reflect the actors' goals and preferences even when consensus among actors is not possible [12].

There have been a significant number of research articles on, and scientific reviews of, the application of MCDA in natural resources management planning. For instance, Mendoza and Martins [13], reviewing MCDA methods from 1970-2006, reported Finland as the country with more publications referring to the use of MCDA in natural resource management (18 out of 57), followed by the USA with 16 publications and Australia with five publications. For additional scientific reviews and application examples, the reader is referred to [1,12-18].

So, how can we work with actors with different interests to identify their preferences, to understand the importance that actors assign to them, and thus support forest management planning using MCDA? Group decision-making (or equivalently, participatory planning) is widely used when many conflicting interests and goals are involved [13]. Group decision-making has become increasingly important in natural resource management because multiple values are treated simultaneously in time and space, and multiple actors can be involved in the decision process $[19,20]$. Thus, the group decision-making technique allows actors to participate and contribute actively to forest management decisions, promoting a more transparent, simple, and easily accessible participatory planning process [3,13].

There are several group-interaction techniques in the fields of behavioral science and decision analysis (e.g., workshops, questionnaires, cognitive mapping, Delphi surveys, focus groups, etc.) that help structure group goals, criteria, and preferences. For example, workshops with participatory discussions promote and broaden the actors' social learning and their understanding of other actors' opinions contributing to reducing conflict of interests [21]. The group decision-making approaches can support (particularly smallscale) forest owners of ZIF, by promoting learning in the group context, and improving group understanding of forest management alternatives. Mainly, participation can be used to increase the legitimacy of a decision and to facilitate the implementation of the chosen forest management models (FMM), as well as to improve the substantive quality of the decision in terms of total social benefit. Moreover, participation can be an end in itself, fulfilling democratic or other local empowerment objectives in the context of forest management [22].

Although the application of the group decision-making approach to forest planning is a relatively recent research area, Diaz-Balteiro and Romero [1] identified a substantial number of research studies related to this approach, confirming an increasing interest in the use of this technique with MCDA. Similarly, Marttunen et al. [10] confirmed that actors' involvement in MCDA has become relatively common, particularly in environmental decision-making. Borges et al. [6] and Maroto [23] note that MCDA and group 
decision-making are powerful techniques for dealing with strategic decision problems and divergent interests, while Ortiz-Urbina et al. [3] highlight the potential of the hybridization of both techniques.

There are few examples in the literature of the application of MCDA to forest management planning in Portugal. Borges et al. [6] applied a combined methodology of participatory workshops and multicriteria decision methods to support the development and negotiation of targets for the supply of ES in two ZIF areas in Portugal-ZIF Chouto Parreira (Chamusca) and ZIF Paiva and Entre-Douro e Sousa (Vale do Sousa). While Xavier et al. [24] employed a methodology based on the multicriteria approach to support decisions for mitigating wildfire risk in a ZIF in the Algarve region, in southern Portugal. However, to our knowledge, a combined MCDA and group-decision making approach has not yet been applied to joint management planning of a forested landscape to help forest actors rank and select the stand-level FMM that best reflect their preferences regarding the supply of ES. This research aims at addressing this gap.

For that purpose, our approach encompasses four stages. First, it uses cognitive mapping $[4,25]$ in a participatory planning session to identify (and discuss with actors) the most relevant criteria and sub-criteria when selecting among forest management alternatives. Second, it evaluates and quantifies the importance of criteria and sub-criteria and the utility of FMM that are better suited to the actors' preferences and concerns, by using a multicriteria questionnaire to address the analytic hierarchy process (AHP) method to judge the importance of criteria and sub-criteria by pairwise comparisons [26,27], the simple multi-attribute rating technique (SMART) to rate the attributes of the alternative FMM [11,28], and a Delphi survey to gather actors judgments [29-31]. Third, it analyzes the convergences and divergences among actors with respect to FMM preferences. Finally, it explores the potential value-added for informing a participatory group decision-making process with a structured decision model that explicitly addresses actors' preferences with respect to criteria, sub-criteria, and FMM alternatives compared to simple questionnaires that actors have previously used to directly rank FMM preferences without the benefit of an explicit decision model [21].

\section{Materials and Methods}

\subsection{Case Study Area}

The Vale do Sousa case study area is located in the North-Western region of Portugal and extends over an area of 14,840 hectares (Figure 1). It includes two joint collaborative management areas: ZIF of Entre-Douro-e-Sousa and ZIF of Paiva. The forests are the primary land use. The predominant species are pure and mixed stands of eucalypt (Eucalyptus globulus Labill) and maritime pine (Pinus pinaster Aiton). The forestland is mainly privately owned, small-scale, and fragmented into multiple blocks. Vale do Sousa is representative of forest management performed in North-Western Portugal, because (a) it has a very large number of small-scale forest owners, (b) eucalypt is the main species, (c) forest management is decided mainly according to individual economic criteria; and (d) the actors interested in forest management have different goals, points of view, concerns, and expectations about forest management planning. 


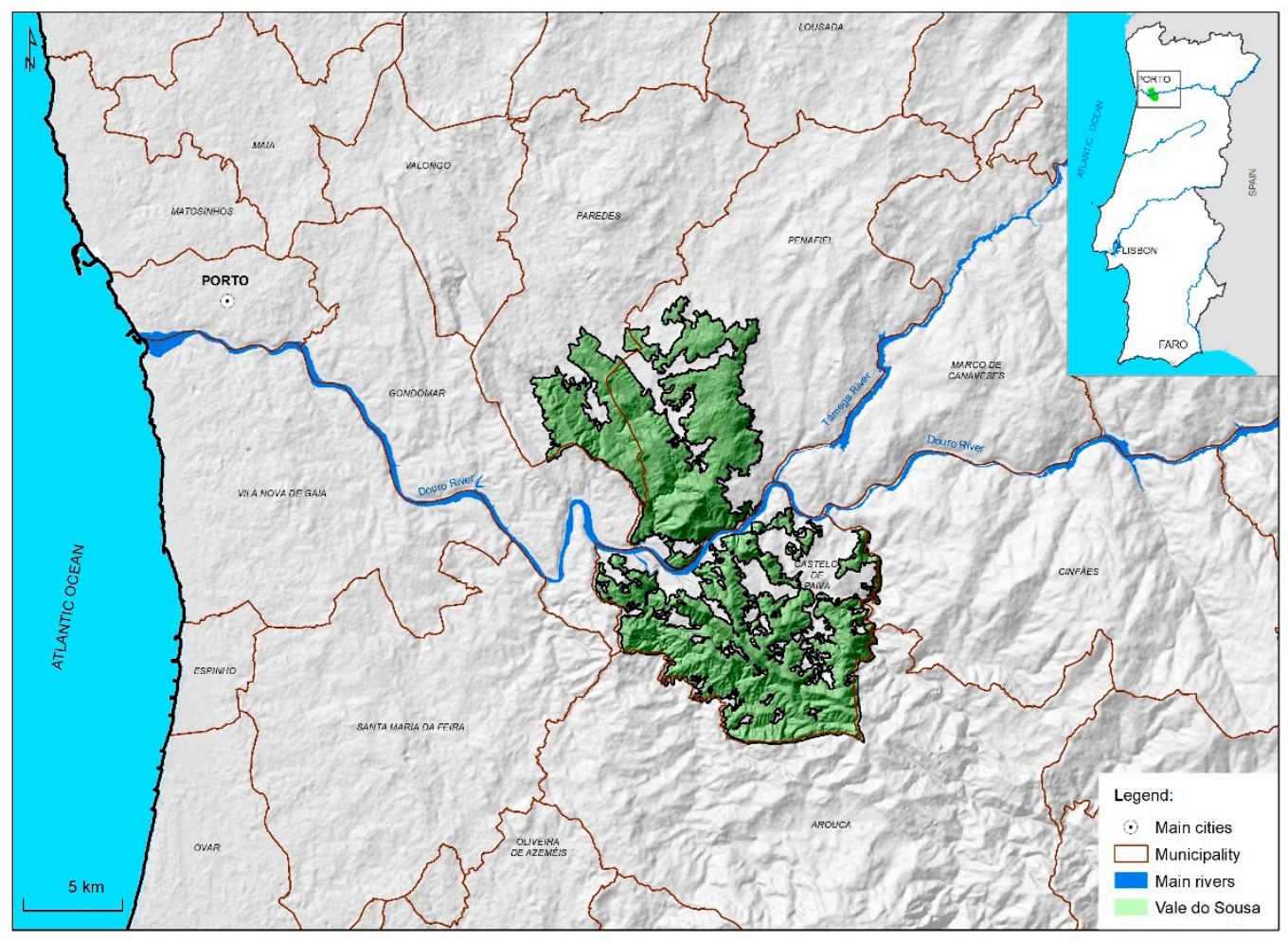

Figure 1. Location of Vale do Sousa case study area.

\subsection{Research Design}

We used a combined MCDA and group decision-making approach to identify the FMM that best reflected the actors' preferences regarding the supply of ES process. We implemented the MCDA process in four stages (Figure 2). The choice of participatory techniques was based on its potential to integrate actors' opinions and preferences in forest management planning.

\subsubsection{Problem Structuring}

We started (stage 1) by structuring the problem based on the information and knowledge gained from former interviews and actor analysis $[29,30]$ and participatory workshop discussions [21].

Our overall problem formulation was motivated by the proposition that the traditional approach to selecting FMM, driven primarily by economic considerations, is unlikely to ensure the sustained long-term provisioning of a broader and balanced range of ES and the diversification of income sources to forest owners and managers [7]. Actor analysis [32,33] identified the problems and conflicts, and the actors that can affect or influence the forest management decisions. A subset of these actors deemed as representative of Vale do Sousa forest management interests was invited to a participatory workshop where they highlighted that the greatest management planning difficulty was to identify the FMM that best respond to their preferences and concerns, in addition to the financial objective [21]. This was influential to characterize the decision context, identify goals and trigger the second stage with key actors. 


\section{MCDA STAGES}

\section{Problem Structuring}

- Define the problem (decision context) and pinpoint the issues

- Identify goals

- Scope participation by identifying key actors

\section{TECHNIQUES}

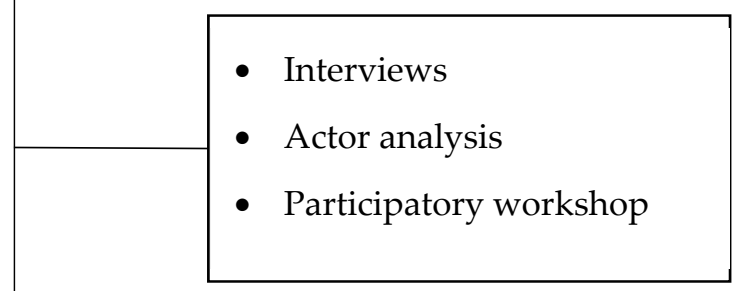

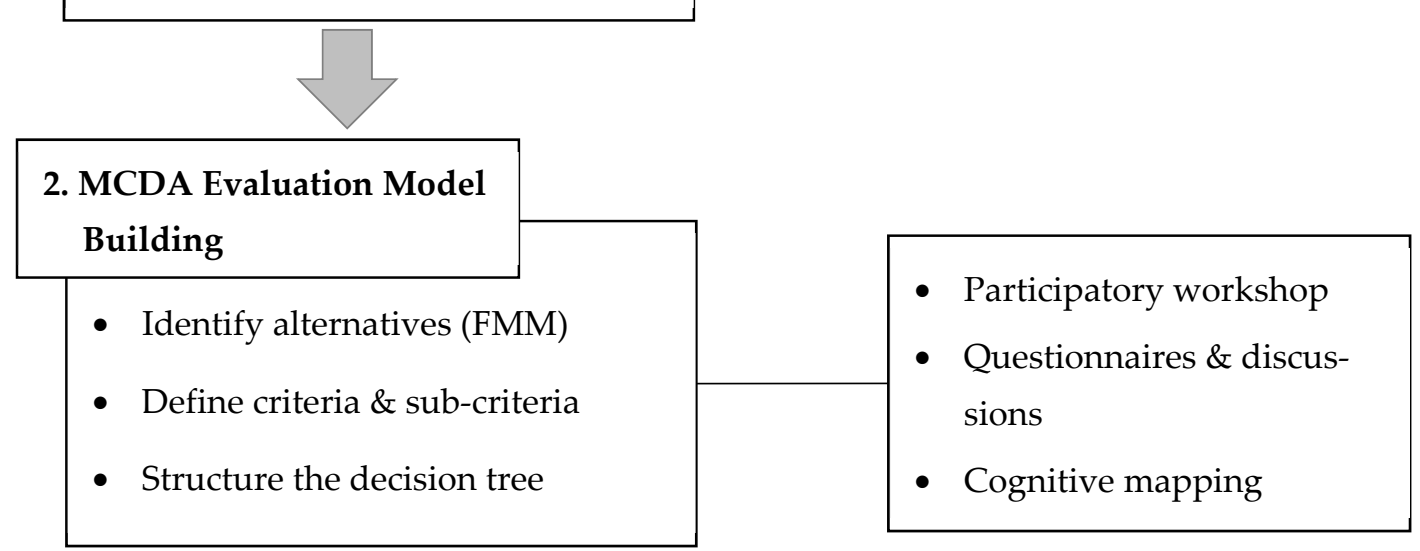

\section{Preferences Modeling}

- Judge the importance of criteria \& sub-criteria, eliciting weights (pairwise comparison)

- Evaluate and rate the alternatives

- Review alternatives performance

- Multicriteria questionnaire

- AHP and SMART

- Delphi survey

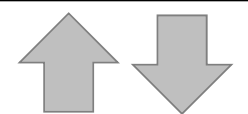

\section{Overall Analysis}

- Assess overall elicitations

- Conduct sensitivity analysis

- Evaluate and compare individual and interest groups results

Figure 2. General stages of the multicriteria decision analysis methodological process and techniques applied. Modified from $[4,11,34]$. 


\subsubsection{MCDA Evaluation Model Building}

In the participatory workshop, the actors identified and agreed further on eight standlevel FMM for Vale do Sousa: mixed maritime pine and eucalypt, mixed eucalypt and maritime pine, pure chestnut, pure eucalypt, pure maritime pine, pure pedunculate oak, pure cork oak, and riparian broadleaves [21]. For this study, we considered all FMM except the riparian broadleaves as this option is only applied to very restricted areas, namely the waterways to provide specific ES (e.g., soil protection, biodiversity).

The problem under analysis was decomposed in a structured way into simple components that could be easily analyzed by the actors. During the workshop, we conducted a half-day session, applying a cognitive mapping technique. A total of 28 actors attended this session (Table 1).

Table 1. Identification of the actors who attended the cognitive mapping session by interest group.

\begin{tabular}{lc}
\hline Interest Group and Type of Actor & Attended the Cognitive Mapping Session \\
\hline Civil Society & 5 \\
Environmental NGO & 2 \\
Forest Certification & 3 \\
\hline Forest Owners & 9 \\
Forest Owners' Association & 2 \\
Forest Owners (Non-Industrial) & 6 \\
Parish Council with Community Areas & 1 \\
\hline Market Agents & $\mathbf{1 0}$ \\
Forest Investment Fund & 1 \\
Forest Services Provider & 1 \\
Forest Services Provider and Wood Buyer & 3 \\
Wood Industry & 3 \\
Wood Industry Association & 2 \\
\hline Public Administration & 4 \\
Forest Authority & 2 \\
Municipality & 2 \\
\hline Total & $\mathbf{2 8}$ \\
\hline
\end{tabular}

Two experienced facilitators conducted the cognitive mapping session. They tried to conduct the session in an impartial, independent, and unbiased way. With this technique, all actors have an equal chance to share and contribute to the discussion.

The session started by asking actors to identify and write on a supplied post-it, their most important criterion in forest management decision-making. We clarified that the purpose was not to reach a consensus but to have a shared understanding of the different criteria. The post-its were placed on a large board and a facilitator read out loud all of them. The facilitator and actors clustered the post-its based on their similarity.

Next, facilitators opened the discussion to analyze each group of criteria, asking actors, "Which criteria should we choose?" and "What is the importance of each group of criteria?" Several opinions, concerns and points of view arose from the lively discussion.

During the session, a researcher assisted the facilitators in organizing the cognitive map using the software Mental Modeler (www.mentalmodeler.org, accessed on 7 December 2020). The actors approved a consensus cognitive map with five groups of criteria and 17 sub-criteria (Figure 3).

To structure the decision tree (stage 2), we converted the cognitive map into a hierarchical structure and complemented it with information from the problem structuring stage. We used the software Criterium DecisionPlus-CDP (InfoHarvest, Inc., Seattle, WA, USA, 1996-2018), a component of the ecosystem management decision support (EMDS) system, [35]), to structure the decision tree which was divided into three parts: six criteria, 12 sub-criteria, and seven alternatives (Figure 4). In structuring the decision tree, we followed a set of key properties highlighted and described by Goodwin and Wright [28] and 
von Winterfeldt and Edwards [36], namely: completeness, operationality, decomposability, essentiality, understandability, non-redundancy, conciseness, and independence.

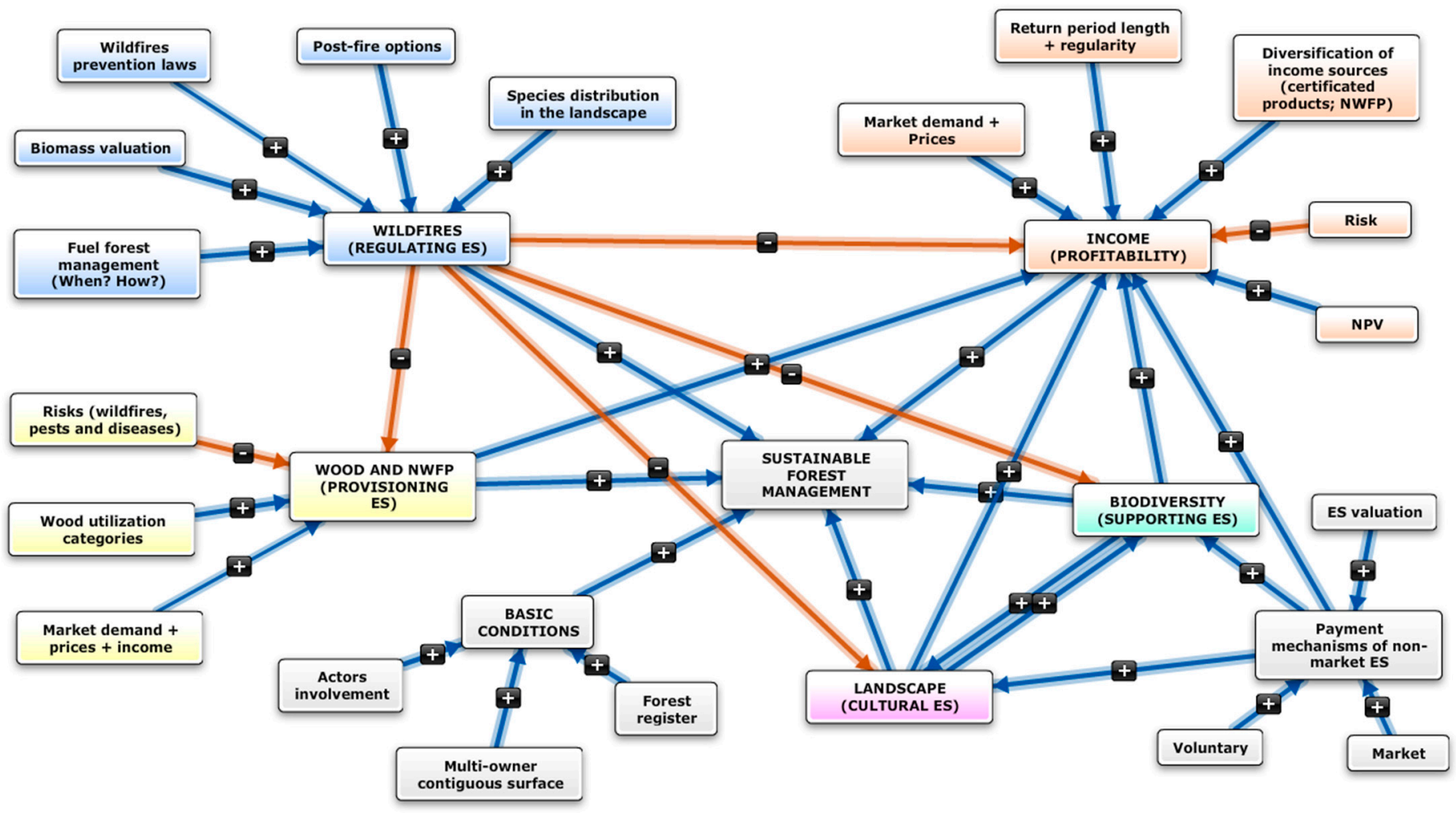

Figure 3. Cognitive map developed with actors during the workshop.

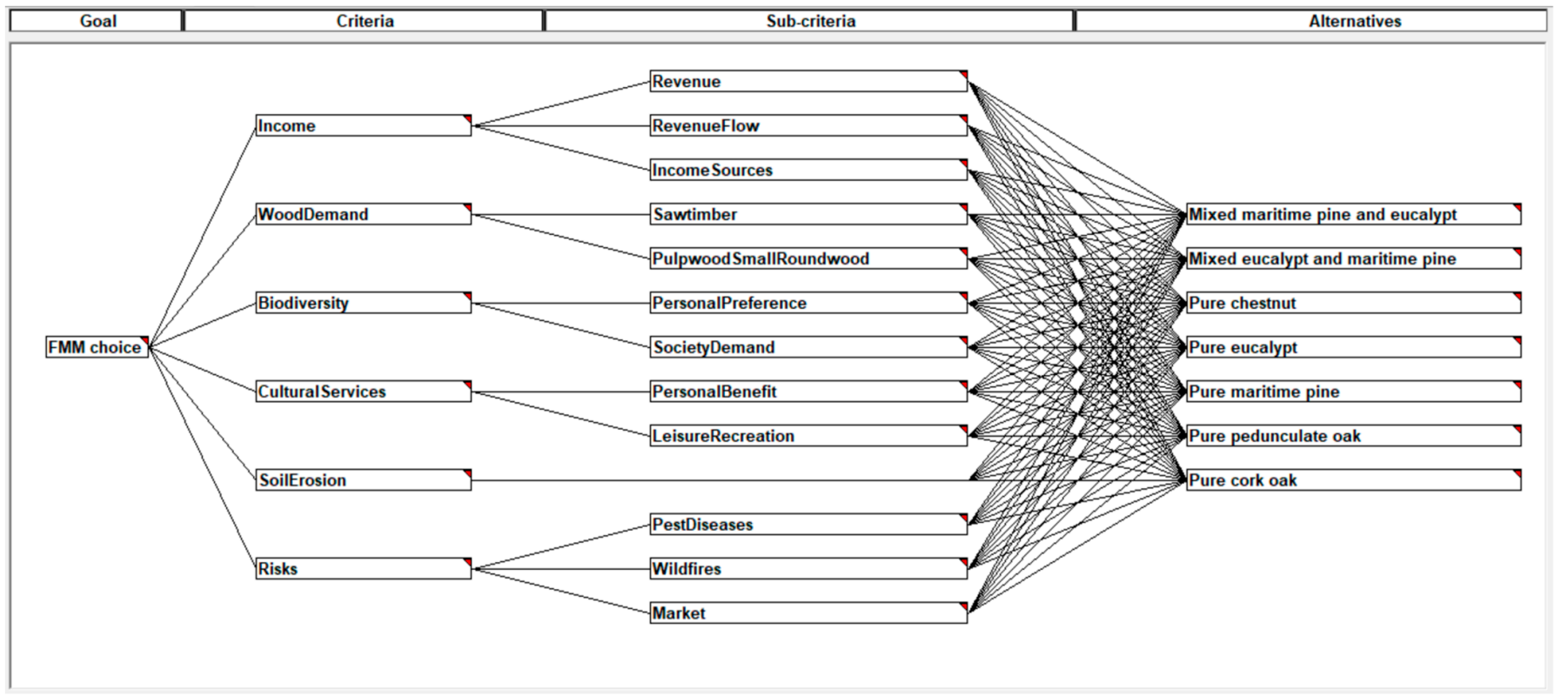

Figure 4. Decision tree (designed by the authors, using the software CDP).

\subsubsection{Preferences Modeling}

Because the actors were not familiar with CDP, we used Excel to structure the multicriteria questionnaire, based on CDP, to facilitate weighting the criteria/sub-criteria and rating the alternatives on the criteria and sub-criteria (utility). The questionnaire was 
organized in three parts, according to the decision tree. We used the AHP to judge the importance of criteria and sub-criteria by pairwise comparisons, and SMART to rate the attributes of the alternatives.

First, in Part I (criteria) and Part II (sub-criteria), we asked each actor to assign the relative importance of each criterion (or sub-criterion) relative to all others, by pairwise comparison on the AHP's standard 9-point scale (Figure 5). We provided a range of nine numerical values (with corresponding verbal descriptions) ranging from 1 (equal) to 9 (absolutely better) to characterize how much more important one criterion was over another. We used the abbreviated pairwise comparison technique in CDP that skips some comparisons to decrease the number of comparisons needed [37], thus expediting actor responses. This method is based on the axiom of transitivity of preference [11].

For each criterion and sub-criterion, a text box with a question was presented to support the analysis. The elicitation was facilitated by a dynamic graph. Therefore, they could change the elicitation if the result did not comply with their expectations, or if they wanted to explore how selecting a different value affected the result. This form of interactive response was provided to ensure that actors understood their elicitation correctly.

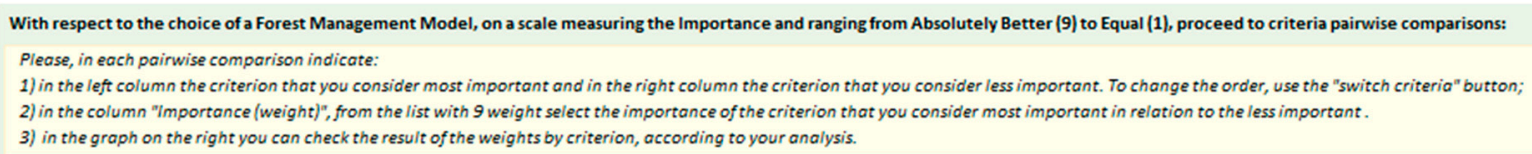

\begin{tabular}{|l|l|l|l|}
\hline Criterion you consider MOST IMPORTANT & Importance (weight) \\
\hline INCOME & Criterion you consider LESS IMPORTANT \\
How important is income when choosing a Forest \\
Management Model?
\end{tabular}

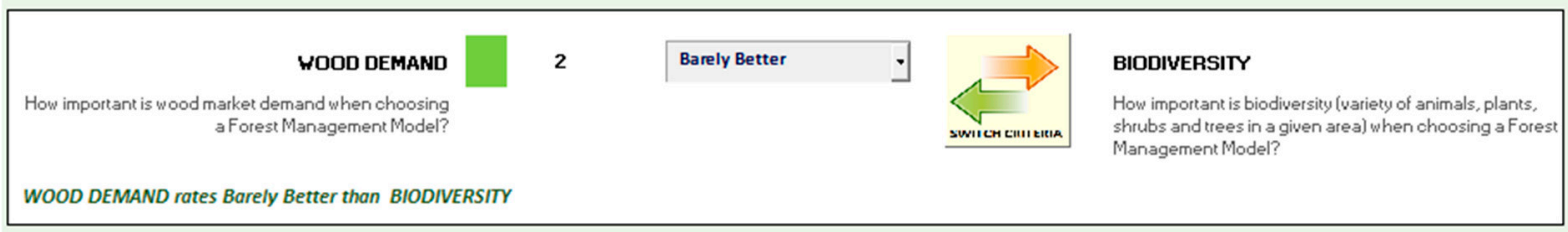

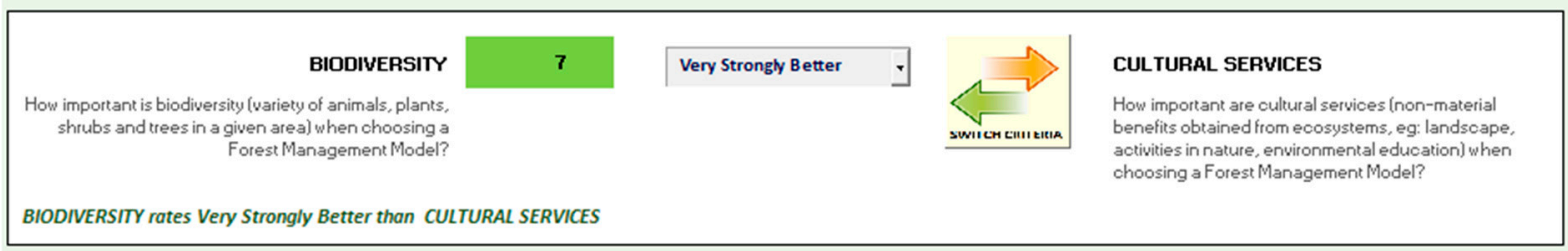

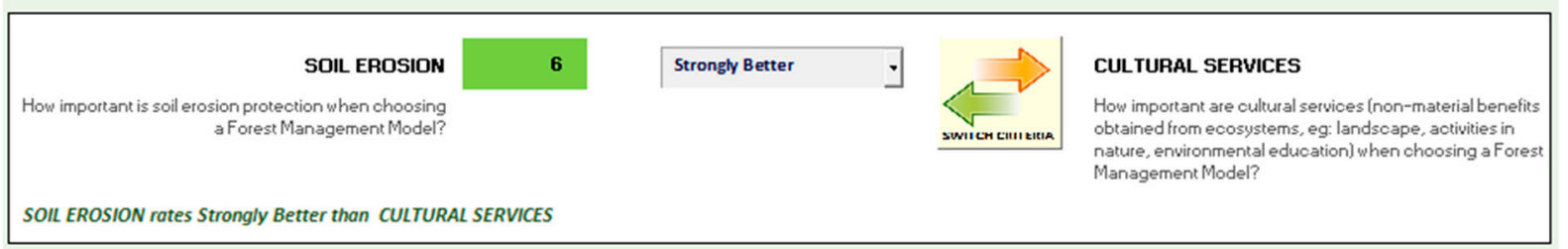

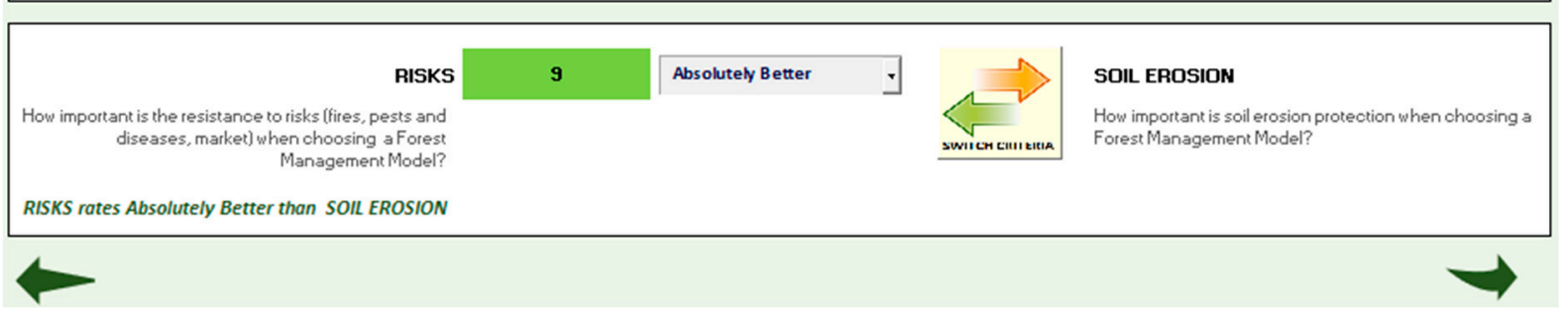

Figure 5. Cont. 


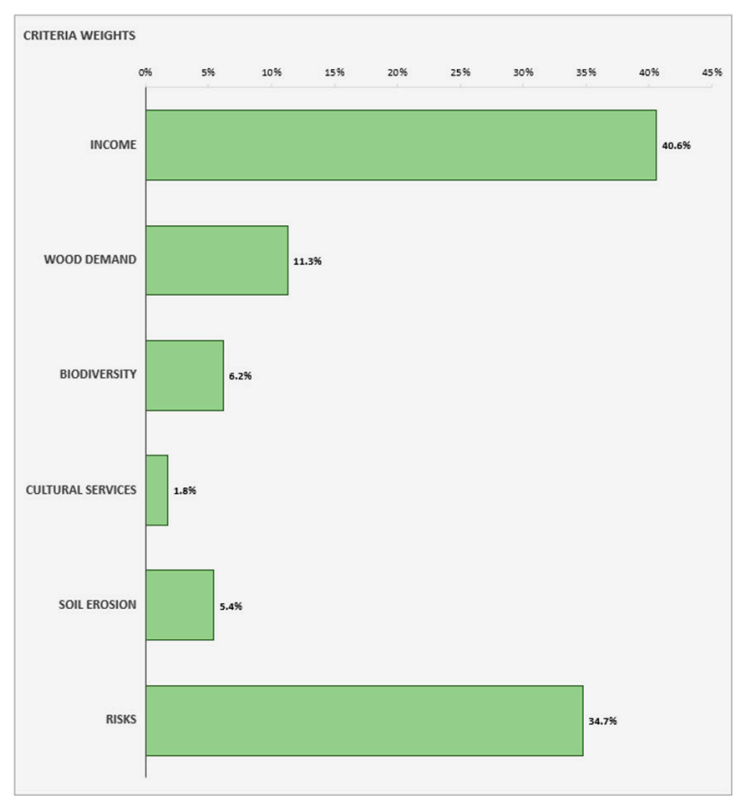

Figure 5. Multicriteria questionnaire: judging the importance of criteria by eliciting weights by pairwise comparisons.

In Part III (alternatives) of the questionnaire, we asked each actor to evaluate each FMM against the lowest-level criteria or sub-criteria (Figure 6), assigning it a utility value, ranging from 0 (very low) to 100 (very high). We asked, "How well does this alternative address or satisfy this sub-criterion?" The goal is to measure the performance of each alternative on that sub-criterion. This gives a measure of how well a FMM performs over all the lowest-level criteria or sub-criteria.

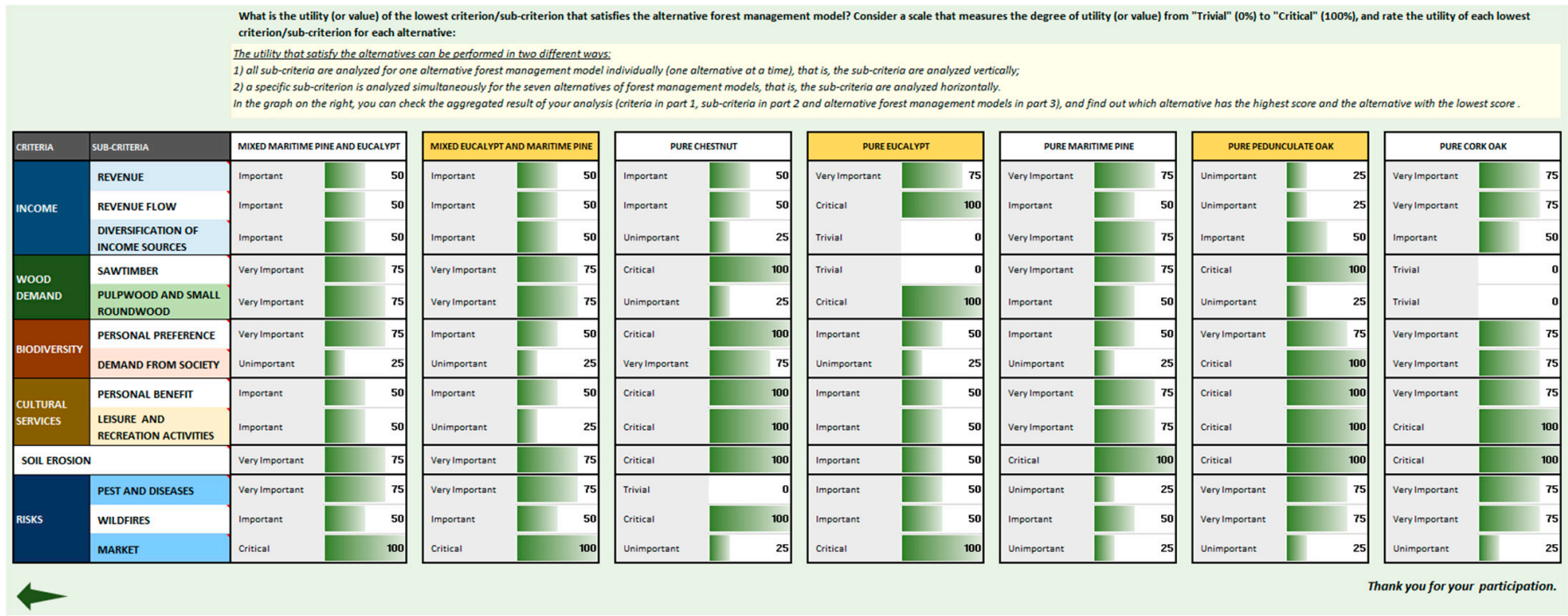

Figure 6. Multicriteria questionnaire to evaluate and rate the utility of the attributes of alternatives (columns) with respect to the lowest-level criteria or sub-criteria (rows).

In the questionnaire, we also provided a dynamic graph with the aggregate outcome of the analysis (Figure 7). We added commentaries to all lowest-level criteria and sub-criteria, so actors could get more information about that topic. The multicriteria questionnaire was pre-tested by three researchers. 


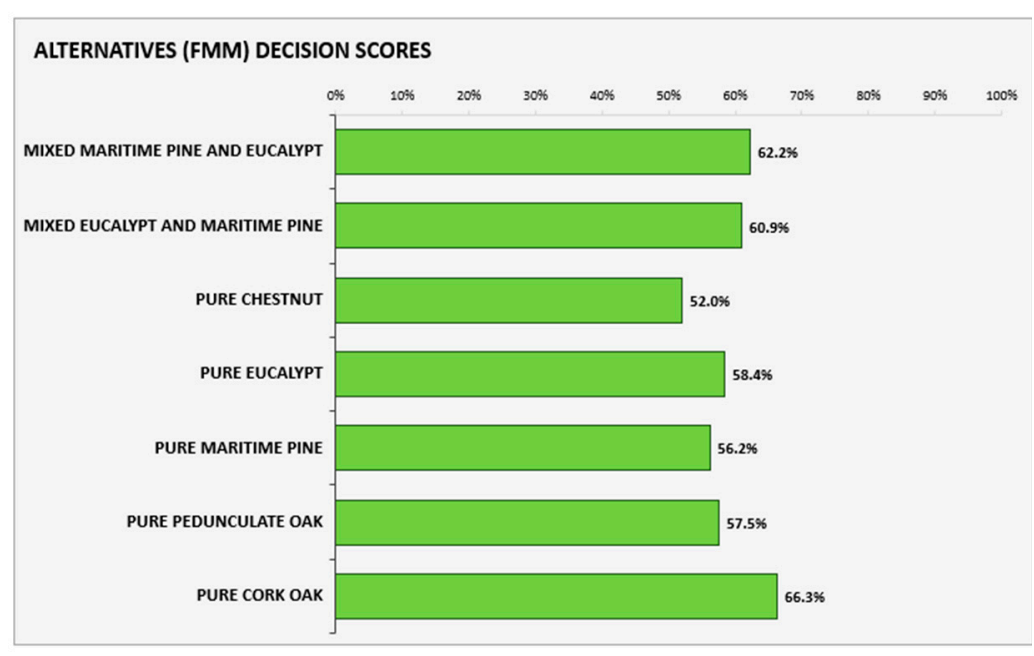

(a)

\begin{tabular}{|l|c|c|}
\hline ALTERNATIVES (FMM) & DECISION SCORE & RANKING \\
\hline MIXED MARITIME PINE AND EUCALYPT & $62.2 \%$ & 2 \\
MIXED EUCALYPT AND MARITIME PINE & $60.9 \%$ & 3 \\
PURE CHESTNUT & $52.0 \%$ & 7 \\
PURE EUCALYPT & $58.4 \%$ & 4 \\
PURE MARITIME PINE & $56.2 \%$ & 6 \\
PURE PEDUNCULATE OAK & $57.5 \%$ & 5 \\
PURE CORK OAK & $66.3 \%$ & 1 \\
\hline
\end{tabular}

(b)

Figure 7. Multicriteria questionnaire: (a) performance of alternatives; (b) ranking of alternatives.

Finally, we used the Delphi technique to give actors an equal opportunity to reflect on and revise their previous answers and preferences and to facilitate the group dynamic process. For the first Delphi round, we sent the multicriteria questionnaire to 60 actors with different interests in case study area (Table 2). About 15 days before the deadline for the submission of the questionnaire, we sent a reminder to the actors who did not respond, explaining how important their contribution was to our participatory approach. We obtained 37 valid questionnaires, i.e., a response rate of $61.7 \%$.

Table 2. Identification of the actors to whom the Delphi questionnaire was sent and those who answered in both rounds, by interest group.

\begin{tabular}{|c|c|c|c|c|c|}
\hline \multirow[b]{2}{*}{ Interest Group and Type of Actor } & \multirow{2}{*}{$\begin{array}{c}\text { Questionnaire } \\
\text { Sent }\end{array}$} & \multirow[b]{2}{*}{$\begin{array}{l}\text { Delphi } \\
\text { Round } 1\end{array}$} & \multicolumn{3}{|c|}{ Delphi Round 2} \\
\hline & & & $\begin{array}{l}\text { Did Not Change } \\
\text { the Responses }\end{array}$ & $\begin{array}{l}\text { Changed the } \\
\text { Responses }\end{array}$ & $\begin{array}{l}\text { Did Not } \\
\text { Answer }\end{array}$ \\
\hline Civil Society & 10 & 7 & 6 & 1 & 0 \\
\hline Environmental NGO & 5 & 4 & 4 & & \\
\hline Forest Certification & 3 & 2 & 2 & & \\
\hline Energy Sector ${ }^{1}$ & 1 & 1 & & 1 & \\
\hline Forest Owners & 19 & 9 & 7 & 1 & 1 \\
\hline Forest Owners' Association & 4 & 1 & 1 & & \\
\hline Forest Owners (Non-Industrial) & 11 & 5 & 4 & & 1 \\
\hline Parish Council with Community Areas & 4 & 3 & 2 & 1 & \\
\hline Market Agents & 23 & 15 & 9 & 2 & 4 \\
\hline Biomass Industry ${ }^{1}$ & 1 & 1 & & 1 & \\
\hline Forest Investment Fund & 2 & 2 & 2 & & \\
\hline Forest Services Provider & 1 & 0 & & & \\
\hline Forest Services Provider and Wood Buyer & 6 & 3 & 3 & & \\
\hline Wood Industry & 6 & 4 & 3 & & 1 \\
\hline Wood Industry Association & 6 & 4 & & 1 & 3 \\
\hline Non-Wood Forest Products Association ${ }^{1}$ & 1 & 1 & 1 & & \\
\hline Public Administration & 8 & 6 & 2 & 2 & 2 \\
\hline Forest Authority & 5 & 3 & & 1 & 2 \\
\hline Municipality & 3 & 3 & 2 & 1 & \\
\hline Total & 60 & 37 & 24 & 6 & 7 \\
\hline
\end{tabular}

\footnotetext{
${ }^{1}$ Additional categories of actors involved in the Delphi rounds that were not present in the cognitive mapping session.
} 
After one month, we sent the questionnaire and a report with the results from the first round to the 37 actors who answered the questionnaire for a second Delphi round. As with the first round, 15 days before the deadline, we sent a reminder to the actors. Six actors changed some of their answers and 24 confirmed that they did not wish to make any changes. We assumed that the seven participants who did not respond did not want to change their responses.

Because of the high rate of unchanged answers (64.9\% confirmation of no change) and the low rate of changed responses $(16.2 \%)$, we did not send the questionnaire for a third Delphi round because we considered that the process had achieved a suitable level of group stability. The goal was not to reach group consensus, but simply to gather well reflected and consolidated actors' preferences and viewpoints.

\subsubsection{Overall Analysis}

The results of the preferences modeling stage were used to complete a CDP model for each actor. Abbreviated pairwise comparisons do not allow for tests of consistency [38]. Thus, to evaluate how robust the actors' responses were to changes in the weights, and for a more transparent analysis, we performed sensitivity analyses, by assessing what would happen if we made small changes in the weights. CDP prioritizes the list of sub-criteria in a model in order of "most sensitive" to "least sensitive", facilitating the analysis of criteria that can influence the decision the most.

A decision model is considered robust when "very substantial changes in the criterion weights are required before another alternative would become selected as the preferred alternative" ([37], p. 191). We considered a model to be robust and stable when the percentage to crossover was greater than $5 \%$ for the most sensitive criterion or sub-criterion (crossover in CDP refers to the absolute change in weight on a criterion that would result in the top-ranked alternative being replaced by another alternative). CDP does not accept simultaneous inputs from multiple participants, so we exported each actor's results (AHP weights and SMART utilities) to Excel to analyze differences among actors. Additionally, to characterize the decision model results by interest group, we synthesized individual judgments on criteria and sub-criteria weights by interest group and overall actors, by applying a consensus convergence algorithm [39] implemented with RStudio (Appendix A).

In our version of the convergence algorithm (Appendix A), we chose to equally weight the contribution of each actor in each group synthesis, whereas a more general implementation of the algorithm would also provide the possibility for actors to rate the importance of each other's weight inputs. We opted for the simpler version of the algorithm as it is both much simpler for actor participation and more egalitarian (e.g., each actor in a group contributes equally to the consensus convergence result). To complete the synthesized CDP model for each group of actors, we calculated the SMART utility score for each attribute of the FMM as the median response of the actors in the group. Finally, to produce a synthesis of the FMM ratings across all interest groups, we calculated a group-weighted CDP utility score for each FMM as:

$$
F M M_{i}=\frac{\left(F M M_{i, C S} \times 7\right)+\left(F M M_{i, F O} \times 9\right)+\left(F M M_{i, M A} \times 15\right)+\left(F M M_{i, P A} \times 6\right)}{37}
$$

where: $F M M_{i}=$ the group-weighted CDP utility score of the $i$-th FMM for a group, and the groups are civil society $(C S)$, forest owners $(F O)$, market agents $(M A)$, and public administration $(P A)$.

\section{Results}

We analyzed the actors' weights and rating results at three levels: (a) individual; (b) aggregated by interest group; (c) aggregated overall actors. The analysis of individual results highlights the subjectivity of the preferences and their variation even when actors are in the same interest group (intra-group analysis). Moreover, it indicates a variation in 
the ratings attributed by the 37 actors. The aggregated analysis provides information about the differences between interest groups as well as about the overall preferences.

\subsection{Criteria}

The criteria that are assigned a greater weight by individual actors are income $(56.8 \%$ of all actors), risks (21.6\% of all actors) and soil erosion (5.4\% of all actors) (Figure $8 \mathrm{a}$ ). Individual actors provide their second and third highest weight to wood demand $(32.4 \%$ of all actors) and biodiversity (16.2\% of all actors), respectively. The smallest weight was given to cultural services ( $27.0 \%$ of all actors rank it as the least preferred criterion).

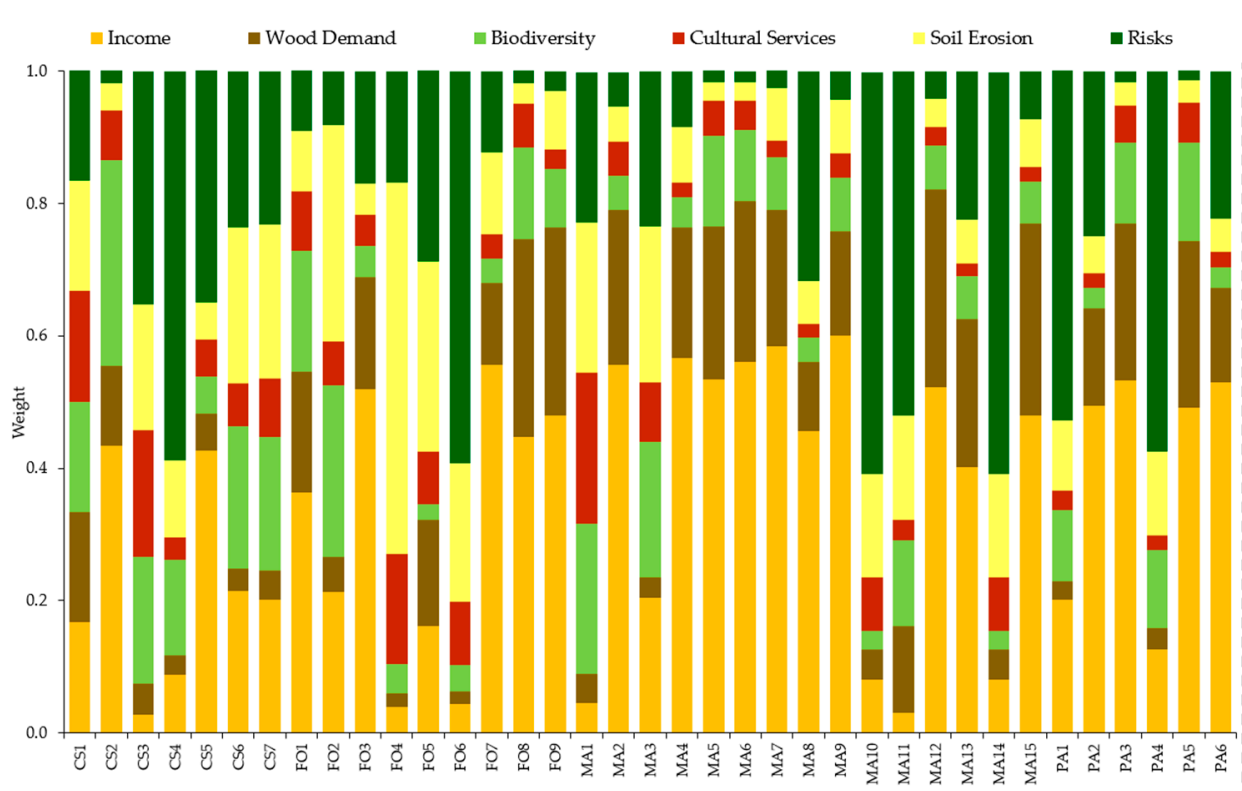

(a)

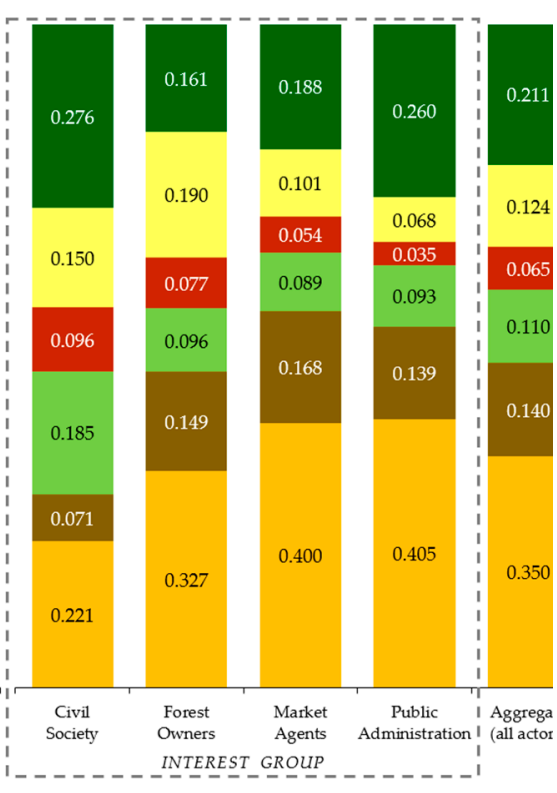

(b)

Figure 8. Weights of criteria: (a) Weights assigned by each actor (CS—civil society; FO—forest owners; MA—market agents; PA-public administration); (b) Aggregated weights by interest group and aggregated all actors. Criteria weights for each interest group were calculated with the consensus convergence algorithm which is presented in the Appendix A and the aggregate weights of all actors' criteria were calculated with Equation (1).

Analyzing the intra-group differences, we found that 10 out of 15 actors from market agents and four out of six actors from public administration agreed to provide the highest weight to the income criterion, while five out of 15 actors from market agents and two out of six actors from public administration agreed to assign the highest weight to the risks' criterion. The actors in these two groups also agreed on the least preferred criterion, assigning the lowest weights to the cultural services (seven out of 15 actors from market agents and three out of six actors from public administration). The actors in the forest owners' group assigned the highest weight to the income criterion (five out of nine actors). The actors from the civil society group considered income (two out of seven actors) and risks (two out of seven actors) as the most important criteria.

Regarding the inter-group analysis (Figure 8b), based on the consensus convergence algorithm, we found that the income criterion was assigned the highest weight by public administration (0.405), market agents (0.400), and forest owners (0.327). In the case of the civil society group, the criterion with the highest weight was risks (0.276) followed closely by income (0.221). In the aggregate analysis of overall actors, we found that the income criterion was assigned the highest weight (0.350) followed by risks $(0.211)$, and the criterion receiving the lowest weight was cultural services $(0.065)$. 


\subsection{Sub-Criteria}

\subsubsection{Income}

The income criterion had three sub-criteria: revenue, revenue flow, and diversification of income sources. About $37.8 \%$ of all actors attributed the highest weight to the diversification of income sources (Figure 9). The intra-group analysis highlighted that in all groups there was a general agreement on the preference for diversification of income sources. In the inter-group analysis, based on the consensus convergence algorithm, the diversification of income sources had the highest weight across the four interest groups, highlighting public administration with the highest value (0.523). In the case of the market agents' group, the difference in weight between the sub-criteria of diversification of income sources (0.379) and revenue flow (0.360) was small, indicating a more or less equal preference for these two sub-criteria. For the overall aggregate results, the diversification of income sources had the highest weight (0.455).

(a)

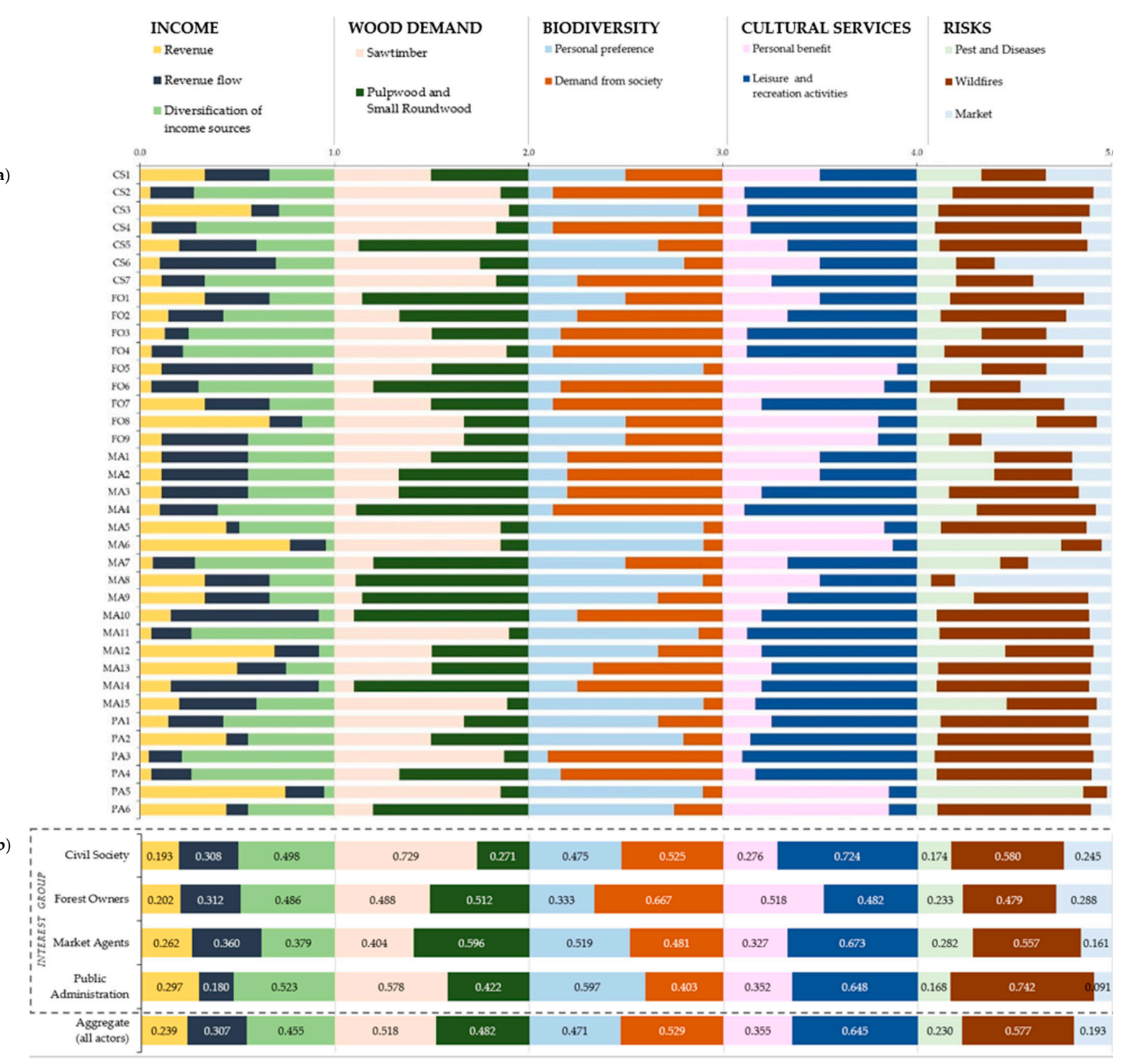

Figure 9. Weights of sub-criteria: (a) Weights assigned by each actor (CS—civil society; FO—forest owners; MA—market agents; PA—public administration)_absolute weights for each sub-criterion can be computed as the product of the relative weight shown here and the associated criterion weight from Figure 8; (b) Aggregated weights by interest group and aggregated all actors. Sub-criteria weights for each interest group were calculated with the consensus convergence algorithm which is presented in the Appendix A and the aggregate weights of all actors' sub-criteria were calculated with Equation (1). 


\subsubsection{Wood Demand}

The preferences for the type of wood are variable among the actors, with preferences divided between the two types of wood: $40.5 \%$ of all actors assigned the highest weight to sawtimber and $37.8 \%$ of all actors to pulpwood and small roundwood (Figure 9). The intragroup analysis highlights a stronger preference for sawtimber by actors in the civil society and public administration groups. In contrast, actors of the market agents group assign the highest weight to pulpwood and small roundwood. Weights for these sub-criteria were variable among actors in the forest owners' group. The aggregate results, based on the consensus convergence algorithm, demonstrate a difference of preferences between the interest groups, with two groups giving highest weight to sawtimber (civil society and public administration) and the other two groups showing a preference for pulpwood and small roundwood (market agents and forest owners). The overall aggregated results indicate the highest preference for sawtimber (0.518) but with only a small difference for pulpwood and small roundwood (0.482), demonstrating a divergence in preferences among actors.

\subsubsection{Biodiversity}

Actors' preferences for the two sub-criteria of biodiversity were highly variable, thus demonstrating low agreement (Figure 9). Results show that $45.9 \%$ of all actors assigned the highest weight to the sub-criterion demand from society and $40.5 \%$ of all actors to personal preference. The intra-group analysis revealed a divergence of opinions in the civil society and market agents' groups. However, there was a higher degree of agreement on preferences in the other two groups. The inter-group analysis by the consensus convergence algorithm, highlights a division between groups. The sub-criterion demand from society has the highest weight in the forest owners and civil society groups, whereas personal preference has the highest weight in the public administration and market agents' groups. The overall aggregated result across all actors revealed that there was poor agreement on preferences among actors, with only a minor difference between demand from society (0.529) and personal preference (0.471).

\subsubsection{Cultural Services}

In the case of the sub-criteria of cultural services, we observed good agreement among actors on their preferences, with $62.2 \%$ of all actors attributing the highest weight to leisure and recreation activities (Figure 9). The intra-group analysis shows that there was a good agreement in the preferences of the groups civil society, market agents and public administration for the sub-criterion leisure and recreation activities. Conversely, there was no agreement in the group of forest owners.

The inter-group analysis by the consensus convergence algorithm showed greater weight of leisure and recreation activities in the case of the civil society, market agents, and public administration groups. The forest owners group assigned the highest weight to personal benefit $(0.518)$, but with a minor difference to leisure and recreation activities (0.482). The aggregate overall result across all actors, shows that the highest weight was attributed to leisure and recreation activities (0.645), with a markedly lower weight assigned to personal benefit $(0.355)$, this demonstrating a reasonable consensus in the preferences of the actors.

\subsubsection{Risks}

Actors' preferences for the three sub-criteria of the criterion risks highlight the importance of the sub-criterion wildfires, with $56.8 \%$ of all actors assigning the highest weight to wildfires (Figure 9). The intra-group analysis showed that there is an agreement in preferences for the wildfires.

The inter-group analysis by the consensus convergence algorithm, highlighted that the highest weight of wildfires across all interest groups. Actors in the public administration group showed the highest level of agreement in their preference for this sub-criterion, 
followed by civil society and the market agents. In the overall aggregate result across all actors, sub-criterion wildfires was weighted 0.577 , with a markedly higher preference compared to pests and diseases (0.230).

\subsection{Alternatives (FMM)}

We evaluated the performance rank of the alternatives to identify which were preferable or desirable by the actors. The analysis of individual preferences showed that for $27.0 \%$ of all actors the FMM with the highest performance was the pedunculate oak (Figure 10a). Also, for $21.6 \%$ of all actors the eucalypt was the FMM with the highest performance. However, $43.2 \%$ of all actors considered this FMM as the least preferable alternative, demonstrating a divergence of opinions among actors.

The intra-group analysis of FMM performance indicates a divergence in preferences. In the civil society group, of the seven actors, two preferred pedunculate oak, two chestnut, and the other two cork oak. Of the nine actors in the forest owners' group, three assigned the highest performance to pedunculate oak and two to cork oak. In these two groups, however, there was an agreement about eucalypt being the least preferred. In the public administration group, two of the six actors gave the highest performance to the eucalypt, while the other four actors had different preferences for FMM. However, there was no agreement regarding the least preferred FMM.

In the market agents group there was a divergence of preferences between the FMM of eucalypt and pedunculate oak. Thus, of the 15 actors, five gave the highest performance to eucalypt, four to pedunculate oak, and three to maritime pine. However, the least preferred FMM were eucalypt (for four out of 15 actors), pedunculate oak (for four out of 15 actors), and chestnut (for three out of 15 actors).

From the aggregated results by interest group (Figure 10b), the highest performance of the pedunculate oak was found in the groups of civil society (0.788) and forest owners (0.631). The lowest performance of FMM for these two groups was the eucalypt (0.314 and 0.411 , respectively). For the group of market agents, the highest performance was the maritime pine (0.686) and the lowest the chestnut (0.562). For the public administration group, the alternative with the highest performance was chestnut (0.827) and the lowest was mixed eucalypt and maritime pine (0.644). For the overall aggregate result, the FMM with the highest performance was pedunculate oak (0.668) followed by chestnut $(0.637)$. The FMM with the lowest performance was eucalypt (0.514).

\section{Contributions by Criteria}

To further evaluate the results of the assessment of FMM by the actors, we analyzed the contributions by criteria to understand which criteria contributed most to the actors decision and which contributed less. To simplify, we analyzed the contributions by interest group.

For the civil society group (Figure 11a), the criteria that most contributed to the alternative with the highest performance, pedunculate oak, were risks $(0.230)$, biodiversity (0.185), and soil erosion (0.150). Regarding eucalyptus, which received the lowest FMM performance rating in this group, the biodiversity and cultural services criteria were assessed as making no contribution to the performance. 


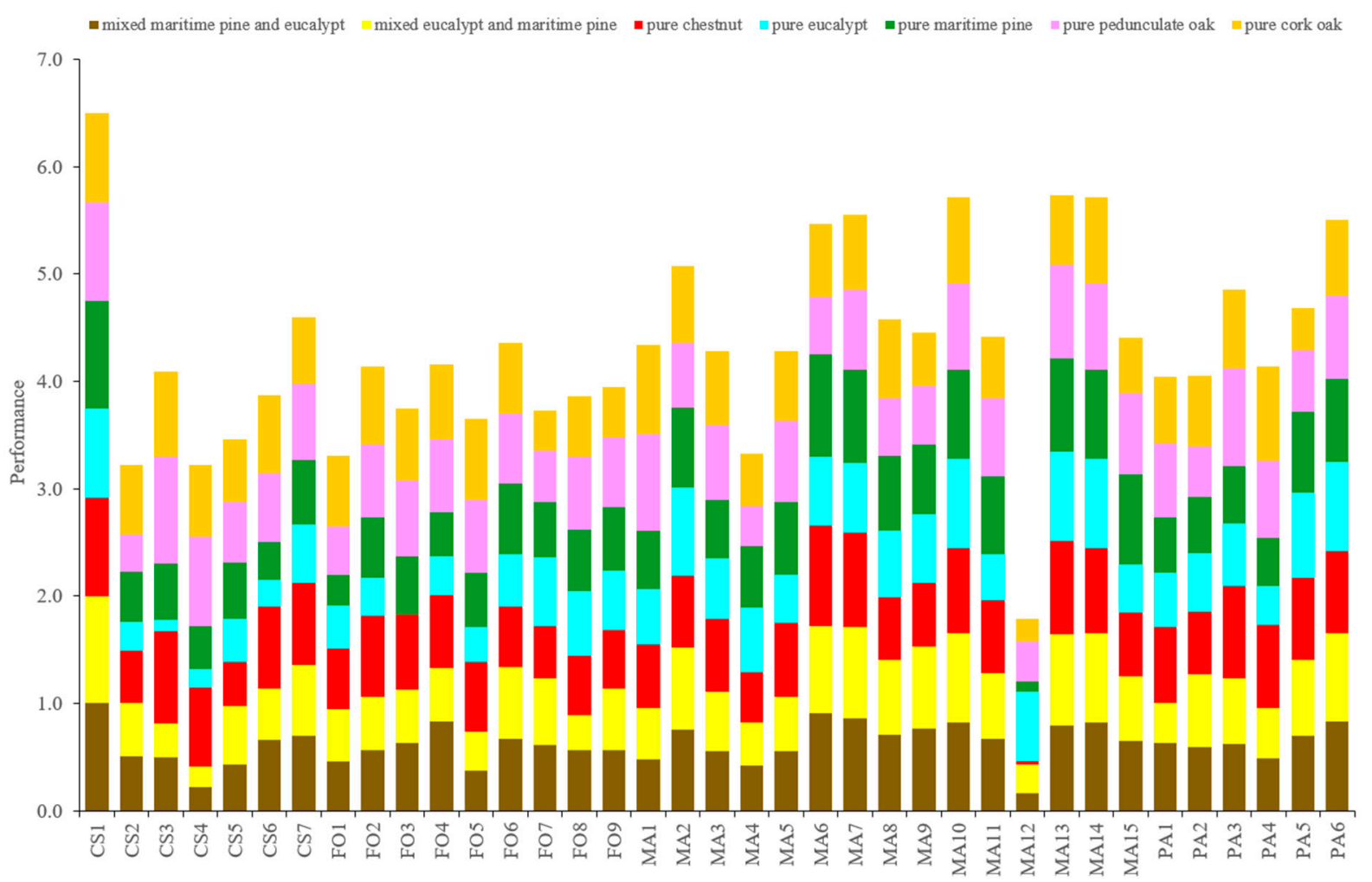

(a)

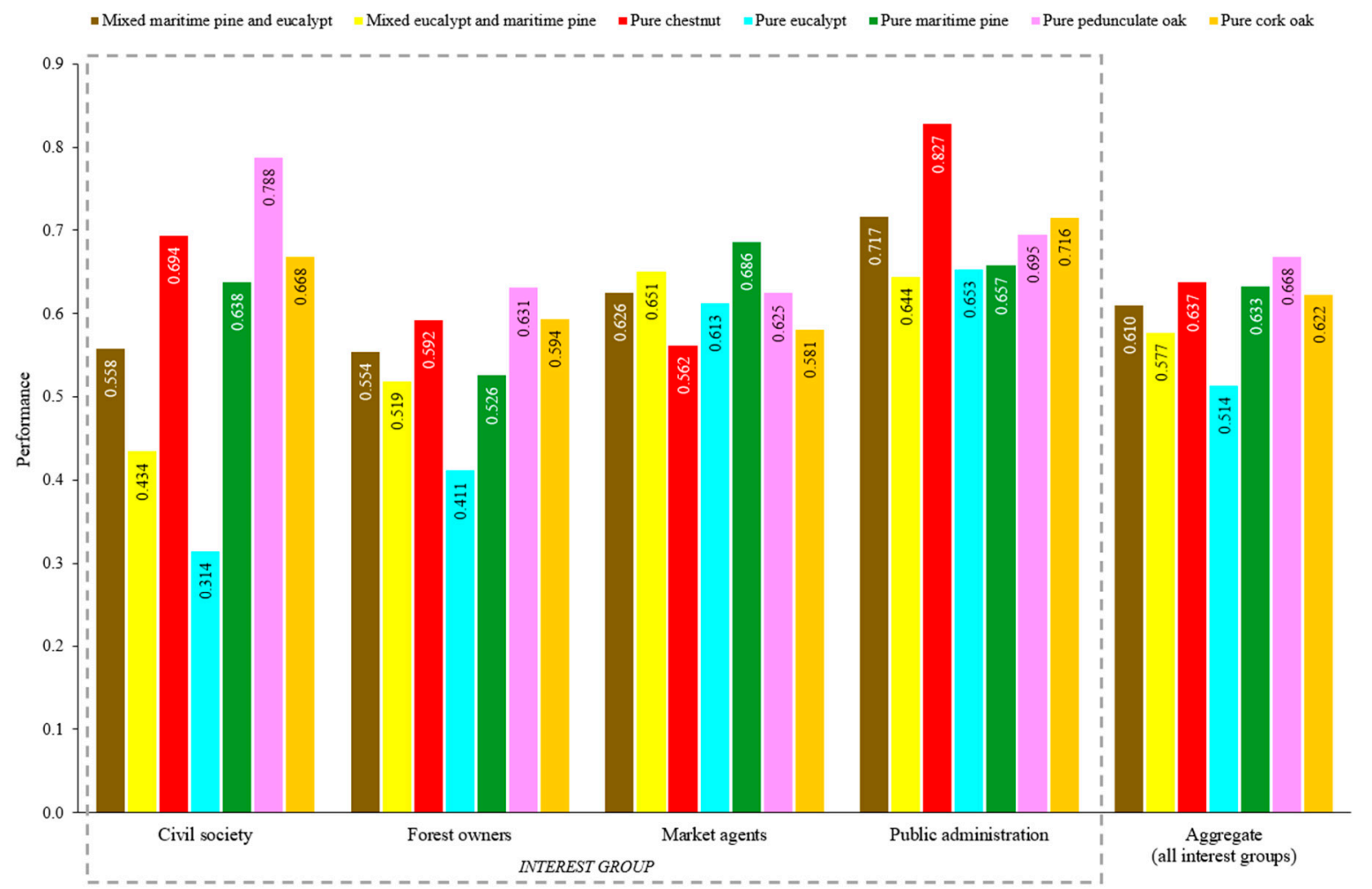

(b)

Figure 10. Performance of alternatives: (a) Performance according to each actor; (b) Performance aggregated by interest group and aggregated across all interest groups. We calculated the SMART utility score for each attribute of the alternative FMM as the median response of the actors in the group. The group-weighted CDP utility score for each FMM was calculated with Equation (1). 


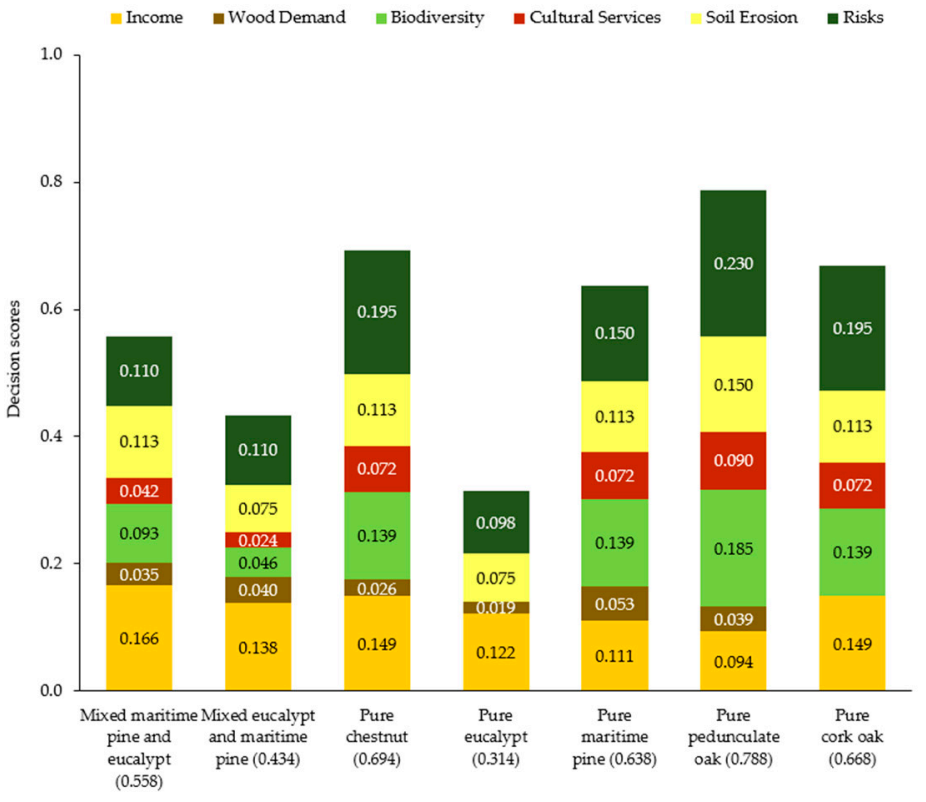

(a)

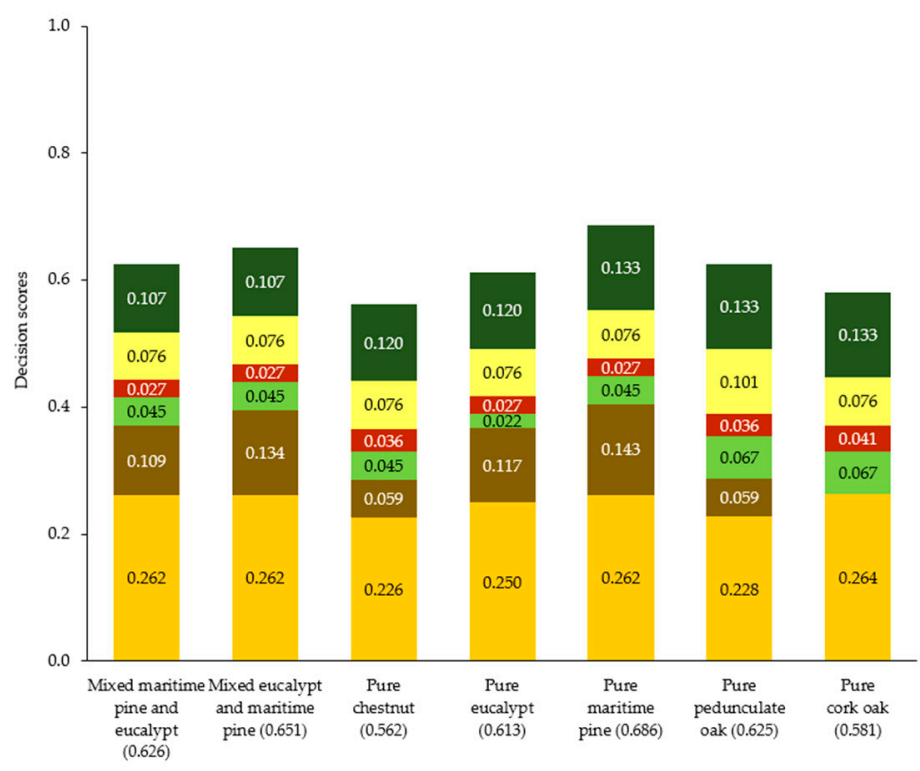

(c)

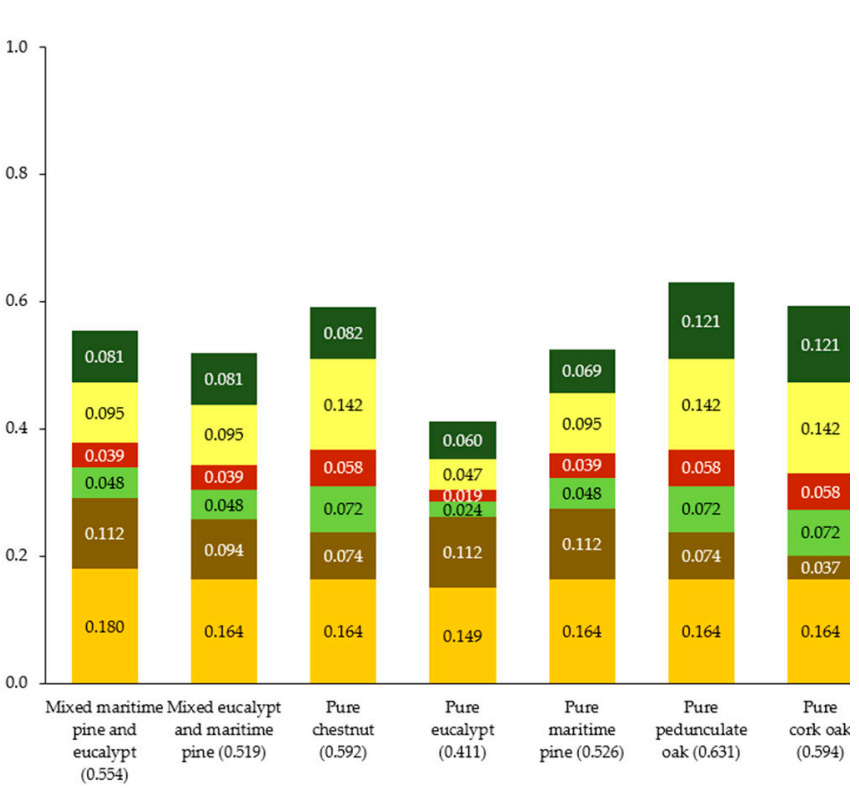

(b)

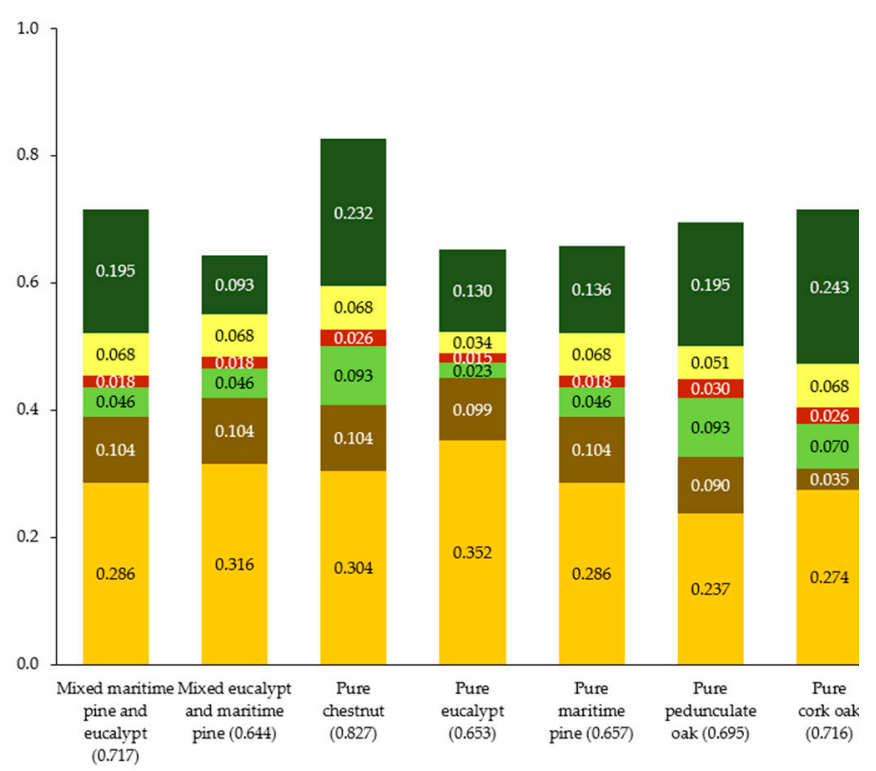

(d)

Figure 11. Contributions by criteria to alternative (FMM) performance as assessed by each interest group: (a) civil society; (b) forest owners; (c) market agents; (d) public administration.

In the case of the forest owners' group (Figure 11b), the criteria that most contributed to the performance rating of pedunculate oak were income (0.164), soil erosion (0.142), and risks (0.121). The cork oak (0.594) and chestnut (0.592) alternatives had very similar performance ratings because the criteria income, biodiversity, soil erosion, and cultural services were assessed as making the same contribution to performance by these FMM. In the case of eucalypt, except for the criterion wood demand, the remaining criteria were assessed as making the lowest contributions to the performance rating compared to the other alternatives.

For the market agents' group (Figure 11c), the three criteria that most contributed to the performance of the preferred FMM, maritime pine, were income (0.262), wood demand (0.143), and risks (0.133). For all alternatives, the criterion with the highest contribution to performance was income, while the one with the least contribution was cultural services. 
For the public administration group (Figure 11d), the criteria of income (0.304), risks (0.232), and wood demand (0.104) are those that were assessed as most contributing to the performance of chestnut, the preferred FMM.

\subsection{Sensitivity Analysis}

Sensitivity analysis can assess the robustness of a decision model by identifying how much the most sensitive criteria in a model would need to change in absolute value (the crossover or criticality value) such that the top ranked FMM is replaced by another FMM due to a change in criteria weights. For this analysis, we considered that a model was robust if the crossover value of the most sensitive criteria was greater than $5 \%$. According to this crossover criterion, among the decision models of individual actors, $32.4 \%$ of all individual actor decision models cannot be considered robust, with a percentage crossover value ranging between $1.0 \%$ and $4.1 \%$.

Analyzing robustness of individual actor decision models by interest group, six of the seven models in the civil society group were considered robust, with minimum crossover values between $11.2 \%$ and $27.1 \%$. In the forest owners' group, seven of the nine models were robust, with minimum crossover values ranging between $5.3 \%$ and $21.8 \%$. In the market agents' group, nine of the 15 actor models were robust, with minimum crossover values ranging from $6.2 \%$ to $56.8 \%$. In the public administration group, half of the actor models were considered robust, with minimum crossover values ranging between $8.1 \%$ and $14.8 \%$. Despite the variability in robustness among individual actors' models when summarized as above by interest group, the aggregate models for the four interest groups all evaluated as robust, with minimum crossover values ranging between $11.6 \%$ (market agents) and $24.8 \%$ (public administration).

\section{Discussion}

In Vale do Sousa, a first assessment was carried out with a simple and direct questionnaire, by asking actors to rank the FMM and ES [21]. In the present study, we further analyzed the actors' preferences to understand which, and by how much, different criteria contribute to their decision or are important when choosing a FMM. The combined MCDA and group decision-making approach supports the actors' participation and incorporates their values and preferences in a structured way, ensuring a certain degree of transparency [40]. The actors who participated in our research represent the forest management interests of Vale do Sousa.

This methodology relied on the values and judgments of actors and their willingness to participate. It allowed for a systematic evaluation of criteria and sub-criteria by abbreviated pairwise comparison and by their perceptions of the utility of seven FMM (mixed maritime pine and eucalypt, mixed eucalypt and maritime pine, pure chestnut, pure eucalypt, pure maritime pine, pure pedunculate oak, and pure cork oak). It provided information about the overall performance of FMM and the relative priorities and ranking of the seven FMM. It further provided a transparent overview of the preferable and consensual FMM and an insight into convergent and divergent preferences, perspectives, and opinions. These outputs can help ZIF managers enhance forest management planning in Vale do Sousa.

Actors need an opportunity to express their concerns and interests, and to learn together $[21,40,41]$. Thus, the development of the cognitive map during the workshop broadened the actors' perspectives on the issues related to forest management decisions, promoting discussions about which criteria were relevant to their choice and should be included in forest management planning. With the cognitive mapping technique, all actors have an equal opportunity to contribute their ideas, while ensuring anonymity when expressing their opinions on the post-its [4]. Hierarchically structuring the decision tree is one of the most important phases of the MCDA process. Thus, we asked actors to reach a consensus on the cognitive map and to validate it in order to bring transparency to the development of the decision tree and the multicriteria questionnaire. 
Next, the weight and rate elicitation process through the multicriteria questionnaire allowed the actors to confirm, through dynamic graphics, the impact of their criteria and sub-criteria preferences on the ranking of the FMM. The Delphi survey technique allowed the actors to think, reassess, and change their opinion, considering the responses of the interest group and the overall actors' answers. It also allowed them to freely contribute to the questionnaire without restrictions or influence from other actors. However, few actors changed their responses in the second round (six out of 37 actors). This suggests that the actors were confident and comfortable with their answers in the first round.

Rather than a simplistic ranking of FMM based on a direct question [21], the MCDA process helped the actors justify their choices as the result is an aggregation of criteria and sub-criteria weights and utilities. Most of the actors who participated in this research had rarely used modern tools or approaches to planning forest management (e.g., MCDA, computerized decision support systems). Use of an MCDA approach was intended to improve the evaluation of the importance of decision criteria and sub-criteria in a participatory decision process. The difference in the weights and utilities emphasized the subjectivity of the actors' preferences. By comparing the overall weights and utilities of different actors it was possible to explore the agreement or disagreement on each criterion, sub-criterion, and alternative.

\subsection{Criteria}

In the cognitive map session, most of the discussion addressed the profitability of the FMM. Of the 28 actors who participated, 11 wrote income on the post-it as the most important criterion in their decision to choose an FMM. The preference for this criterion was confirmed in the multicriteria questionnaire results, with $56.8 \%$ of the actors giving it the highest weight. Because most of the ZIF area is privately owned, the main objective of forest owners is profitability. In contrast, actors from the parish council, who manage community areas with the objective of a recreational forest for local populations, considered soil erosion the most important criterion.

Most actors stated that if a forest management unit is not profitable, the forest owners would tend to abandon it. The results of the multicriteria questionnaire also revealed that $21.6 \%$ of actors placed a high weight on risks because it could lead to significant losses of forest investment. Overall, these findings led us to conclude that there was a consensus among the actors on the preference for the criteria of income and risks. The civil society group considered risks as the most important criterion and biodiversity as the third. In the interviews [33], the actors of this group defended the importance of biodiversity as an ES to be promoted in Vale do Sousa. However, this was not verified in the results. Moreover, the actors also agreed on the least preferred criterion being cultural services, reinforcing the findings by Marques et al. [21,33]. This may be due to conflicting interests between the outdoor motorized recreation activities, particularly the unorganized activities, and the forest owners and managers [33].

\subsection{Sub-Criteria}

Overall, the actors agreed on their preferences for the sub-criteria of the income, risks, and cultural services criteria, but there was poor agreement among actors on the sub-criteria of the wood demand and biodiversity criteria.

For the sub-criteria of income, most actors assigned the highest weights, first, to diversification of income sources and, second, to revenue flow. These results confirmed participatory discussions. Due to the risks of wildfires and pests and diseases, the actors highlighted the importance of ensuring diversification of income sources, particularly through a multifunctional forest. Forest management requires several maintenance interventions with associated costs, and actors stressed that ensuring a revenue flow made it easier to meet these expenses and manage the forest.

For the risks' criterion, there was agreement on the preference for the sub-criterion wildfires. This can be explained by the frequency of wildfires. The substantial financial 
losses that resulted from wildfire occurrences in Vale do Sousa in 2016 and 2017 even led to the abandonment of forest management by some forest owners due to the lack of financial resources. Actors gave the second-highest weight to pests and diseases. In the last decade, forest owners and managers had to deal with two pests, which have affected the forest stands of Vale do Sousa. First, the pine nematode (Bursaphelenchus xylophilus), and second the Gonipterus platensis in the eucalyptus stands. The recurrence of wildfires and pests, in combination with low financial incentives and investments, may be discouraging forest owners and managers from managing the forest. These findings confirm the actor analysis results [33].

For the cultural services criterion, most actors attributed a higher weight to leisure and recreation activities. This preference can be explained by the importance that forests have for recreational activities in the ZIF. There is a growing demand in Vale do Sousa for natural spaces by society and by sports enthusiasts and urban people (e.g., from Porto). However, half of the actors from the forest owners' group considered that forests should be for personal benefit because it is private, as opposed to public forest land.

There was no agreement among actors about the type of wood because half preferred sawtimber and the other half preferred pulpwood and small roundwood. Currently, the dominant FMM in Vale do Sousa is eucalypt (pure or mixed) for pulpwood to address the market demand of the pulp and paper industries, but sawtimber from forest stands over 40 years old commands higher prices than pulpwood and small roundwood. However, due to the high frequency of wildfires in Portugal, the availability of sawtimber on the national market is limited. This divergence of opinion on the type of wood can be explained by a conflict between short-term financial needs and longer-term concerns with forest diversity.

Although there was a diversity of actors' preferences for biodiversity during the cognitive mapping discussions, actors emphasized that this was an important ES in Vale do Sousa. Moreover, they were in general agreement regarding the need for adequate policy tools to promote and protect the supply of biodiversity. Some forest owners stated that although society demands biodiversity, people are not willing to pay for this ES, thus compensating forest owners for their income loss. These two sub-criteria were perhaps the most controversial among actors.

\subsection{Alternatives}

The findings demonstrate that actors' preferences are divided between native broadleaf species (pedunculate oak, cork oak, and chestnut) and exotic species (eucalypt), and similarly between the forest product types, sawtimber (pedunculate oak and chestnut) and pulpwood (eucalypt).

In Vale do Sousa, there are four dominant FMM: pure maritime pine, pure eucalypt, mixed maritime pine and eucalypt, and mixed eucalypt and maritime pine. In the simple FMM questionnaire [21], actors ranked these FMM as the first, second, third, and fourth preferred models, respectively, confirming the current forest management options implemented in Vale de Sousa. However, in the multicriteria questionnaire, preferences for the eucalypt FMM were contrasting, because $21.6 \%$ of all actors assigned the highest performance to this model and $43.2 \%$ of all actors assigned to it the lowest performance. These results suggest that there are actors, mainly from the market agents' group, who prefer to maintain the same FMM (eucalypt) due mostly to its shorter rotations and the frequency and severity of wildfires. In addition, since eucalypt and maritime pine are the dominant species in Vale do Sousa, we expected a higher ranking of these FMM by forest owners' group. However, they ranked these FMM low, in contrast to the current land use. The latter are prone to increase due to climate change [42]. Thus, climate change has an indirect impact on the ranking of FMM by forest owners and managers.

More than half of actors attributed the highest performance to FMM that encompass native species and longer rotations (pedunculate oak, cork oak, and chestnut). These preferences suggest a willingness to implement conversion of species in the ZIF of Vale do Sousa. When the actors answered the multicriteria questionnaire, the Portuguese 
government had already published legislation that restrict the expansion of eucalypt plantations. This constraint may lead some actors to consider other FMM. Moreover, during the cognitive mapping discussions, forest owners and managers stressed that they are open to the possibility of converting forest species, replacing eucalypt with native species if they are financially compensated for the loss of income. Such a change in species choices would tend to promote a diversification of forest species and ES in Vale do Sousa. These findings reinforce the actors target for a multifunctional and profitable forest $[21,33]$.

\subsection{Comparison to Other MCDA and Group Decision-Making Studies}

The few examples of the application of MCDA to forest management planning in Portugal do not allow an in-depth comparison with our results. Borges et al. [6] used a multicriteria decision-making approach combined with a decision support system to support the negotiation of targets for the supply of ES. Most of the actors who participated in their study also participated in our research. Nevertheless, the authors did not analyze the actors' preferences for criteria or ranked the ES or FMM. However, our results can be compared with studies from other countries reported in scientific publications. For example, Fontana et al. [43] used MCDA to rank three land-use alternatives and their ES provision in the Eastern Alps, Italy. While in our research the actors weighted income highest, in Italy the profitability ranked lowest and protection against avalanches, landslides and rock fall high. However, in both countries, the actors gave the lowest weight to cultural services. Nordström et al. [40] used AHP for planning an urban forest in Sweden. The authors worked with four social groups (timber producers, environmentalists, recreationists, and reindeer herders) to identify the criteria, elicit the preferences and ranking three forest plans. The authors concluded that actors' participation in the decision process promoted a better structuring of the problem and more transparency for actors, which was also confirmed in our research. Segura et al. [44] implemented a collaborative management process and assessment of ES in Valencian Community (East Spain). They worked with three groups (decision makers, technical staff, and other stakeholders) by identifying ES and eliciting preferences using the AHP method. All actors considered the maintenance of ES as the most important function. In our research and in cognitive map session, the actors also discussed this topic and agreed that ES should be maintained, and their diversification promoted in Vale do Sousa. In Valencia, actors from the three groups considered the forest products (cork, timber, biomass, mushrooms) as the most important provisioning services. In our research, wood provision was considered as the third most important criterion (aggregate results).

\subsection{Limitations of the Study and Future Improvements}

The participatory MCDA process can be time-consuming and demanding for the research team. One year went by, since the first workshop, in which the cognitive map was developed with the actors until the presentation of the MCDA results in a second workshop. During that time there were several interactions with the actors, not only by sending out the questionnaire, but also follow ups to encourage response. Moreover, identifying and contacting forest owners who were willing to answer the questionnaire was both challenging and time-consuming.

We identified three issues throughout the combined MCDA and group decisionmaking process that can be improved by future research. First, not all actors were proactive during the cognitive mapping discussion. Some actors talked more freely during the personal interview for actor analysis [33] than in the workshop open discussion. In the interviews, the actors were very comfortable sharing their experiences, preferences, and concerns related to forest management. Although the facilitators tried to get every actor to participate in the discussion, in some situations, some actors were more vocal and tended to dominate the discussion. This behavior tends to inhibit other actors from participating out of concern for how their contribution may be received by their peers. In this framework, 
it is necessary to develop strategies that allow every actor to participate equally in the discussions without hesitation.

Second, a relatively small number of private non-industrial forest owners responded to the multicriteria questionnaire. We sent 11 questionnaires to private forest owners, but we only received five responses. We asked the local Forest Owners Association (AFVS) to identify more forest owners who could answer the questionnaire, and we contacted them by email or telephone to find out if they were willing to answer the questionnaire. Yet, many forest owners were either not available or did not want to participate. Of the eight forest owners that participated, three managed only eucalypt and five have eucalypt and yet they are converting the stands at the end of the rotation to native species. Thus, the forest owners' group in our research may not be fully representative of the forest owners who keep the eucalypt FMM in ZIF of Vale do Sousa. Thus, to guarantee more responses from a more diversified set of forest owners to the multicriteria questionnaire, future research can encompass personal visits to gain the forest owners' trust, engagement, and willingness to participate in the multicriteria questionnaire.

Third, although we had designed the questionnaire to be relatively simple and intuitive, with dynamic graphs to provide information about the implications of choices, some actors may have had difficulties understanding it, and because of that they may have not responded. Due to budget constraints, it was not possible to visit the actors individually, to explain the questionnaire and how to fill it out. These limitations are typical of current MCDA approaches [19]. Thus, to promote a higher level of responses, future research may expand our approach to include personal visits to the actors who did not understand the questionnaire to explain the questions so that they may feel more confident and comfortable to provide answers. Alternatively, it may be expanded to include a decision conference (as explained by Phillips, [45]), creating a multi-voiced decision model (as described by Murphy, [11]), to allow actors to discuss and interactively visualize the impact of weights and utilities on the performance of the alternatives. In that decision conference, a facilitator may conduct the brainstorming, help actors with eliciting and rating the decision model, analyze and discuss the outcomes, and refine the model if necessary [11].

\section{Conclusions}

This study successfully combined MCDA and group decision-making processes as an approach to rank seven FMM and enhance joint forest management planning. Consensus was not the main goal of this research, but, rather, the understanding of actors' opinions and interests, and its variability among individuals and groups. The development and application of this approach requires an effort of conceptualization, time for data gathering, to interact with the actors and to analyze all the information collected. Nevertheless, it fully achieved its objective to select FMM and support landscape-level collaborative planning.

Income was the criterion with the highest level of agreement among actors in a decision on the choice of FMM. This result led us to conclude that actors generally depend on the eucalypt FMM for its ability to provide a short-term flow of income. Yet, they expect to change this paradigm. They also want a more multifunctional forest with more diversity of species that may contribute to diversify their income sources, with a revenue flow, that is resilient to the risks of wildfires and pests and diseases. According to the participatory discussion, wildfires are the risk that actors considered the most impactful to forest management, and, as stated by some actors, broadleaves FMM may contribute to reducing this risk. Some actors argued that a forest with a diversity of species could slow the progression of pests and diseases. These reasons may explain the higher and similar performances of the broadleaves FMM (pedunculate oak, chestnut, and cork oak).

Forest owners and managers are open to possibility of replacing eucalypt FMM with other FMM, if they are financially compensated. Moreover, forest owners argued that they should also be financially compensated for promoting other ES, such as biodiversity and cultural services, from which society benefits most. These ES are non-marketable services, so it is not easy to calculate the corresponding financial compensation. In gen- 
eral, there is an openness to change the selection of FMM in Vale do Sousa to achieve a multifunctional forest.

We believe that three key elements contributed to the success of the application of the combined MCDA and group decision-making process. First, the choice of actors to represent a wide variety of interests and points of view on the forest management of Vale do Sousa. Second, the promotion of participatory and interactive discussion in the identification of criteria and alternatives to be considered in MCDA. This stage also promoted social learning and a shared understanding of the actors' different points of view. The consensual cognitive map was crucial in structuring the decision tree and the multicriteria questionnaire. Third, the opportunity for actors to reassess and change their responses, considering the results of other actors' responses.

The MCDA and group decision-making process allowed actors to explore the impact of criteria and sub-criteria weights and FMM utilities on the performance of each alternative. It contributed further to better understand the opinions and preferences of other actors. A forest management plan for the entire ZIF that integrates these preferences and opinions is likely to be more easily accepted by the ZIF members who participated in this decision-making process. Participatory forest management decisions raise the actors feeling of belonging, social awareness, and shared influence, potentially improving the changes of implementation of better forest management. The combination of MCDA and group decision-making is thus a useful approach towards the fulfillment of one of the ZIF objectives-joint forest management. The application of this methodology demonstrated that actors are interested in a profitable and multifunctional forest that is resilient to the risks of wildfires and pests and diseases. ZIF managers may want to consider integrating these findings into the next revision of the forest management plan of Vale do Sousa.

The results from this study will be used in the next step of ongoing research of participatory processes. When several FMM alternatives provide different levels of ES, there should be a consensus-building exercise among actors before its implementation by a plan. Ideally, a decision would be taken by consensus and only then implemented by ZIF managers and forest owners. In a subsequent study, we will apply a focus-group technique to discuss negotiable and consensual forest management solutions for Vale do Sousa. At this stage, the actors are already aware of the results obtained from the participatory process undertaken to date, namely the preferences and points of view of other actors and the potential conflicting interests.

Author Contributions: Conceptualization, M.M. (Marlene Marques), K.M.R. and J.G.B.; methodology, M.M. (Marlene Marques), K.M.R., M.M. (Marco Marto), M.L., C.C., P.J.M. and J.G.B.; software, M.M. (Marlene Marques), K.M.R., M.M. (Marco Marto) and P.J.M.; validation, M.M. (Marlene Marques), K.M.R., C.C. and J.G.B.; formal analysis, M.M. (Marlene Marques) and K.M.R.; investigation, M.M. (Marlene Marques), K.M.R., M.M. (Marco Marto), M.L. and J.G.B.; resources, M.M. (Marlene Marques), K.M.R. and J.G.B.; writing—original draft preparation, M.M. (Marlene Marques); writingreview and editing, K.M.R., J.G.B., M.M. (Marco Marto), C.C., M.L. and P.J.M.; project administration, J.G.B.; funding acquisition, J.G.B., M.M. (Marlene Marques) and M.M. (Marco Marto) All authors have read and agreed to the published version of the manuscript.

Funding: This research was funded by the European Union's Horizon 2020 Research and Innovation Programme (grant agreement number. 676754) (ALTERFOR), by the Marie Skodowska-Curie Research and Innovation Staff Exchange (RISE) within the H2020 Work Programme (H2020-MSCA-RISE2015) (SUFORUN), by the Portuguese Science Foundation (FCT) namely through the Ph.D. grant of Marlene Marques (PD/BD/128257/2016), the Ph.D. grant of Marco Marto (SFRH/BD/108225/2015), the Forest Research Center Project UIDB/00239/2020, and the BIOECOSYS project (grant number LISBOA-01-0145-FEDER-030391, PTDC/ASP-SIL/30391/2017).

Disclaimer: The use of trade or firm names in this publication is for reader information and does not imply endorsement by the U.S. Department of Agriculture of any product or service.

Data Availability Statement: The data that support the findings of this study are available from the corresponding author upon request. 
Acknowledgments: We thank Susete Marques for testing the questionnaire and helping during the workshop and Brigite Botequim for helping during the workshop. We thank Sandra Pinto for helping identify and contact forest owners from Vale do Sousa. We warmly thank all the actors who have participated in the Workshop and/or answered the Multicriteria Questionnaire.

Conflicts of Interest: The authors declare no conflict of interest.

\section{Appendix A}

Code A1. R code to calculate the consensus convergence algorithm.

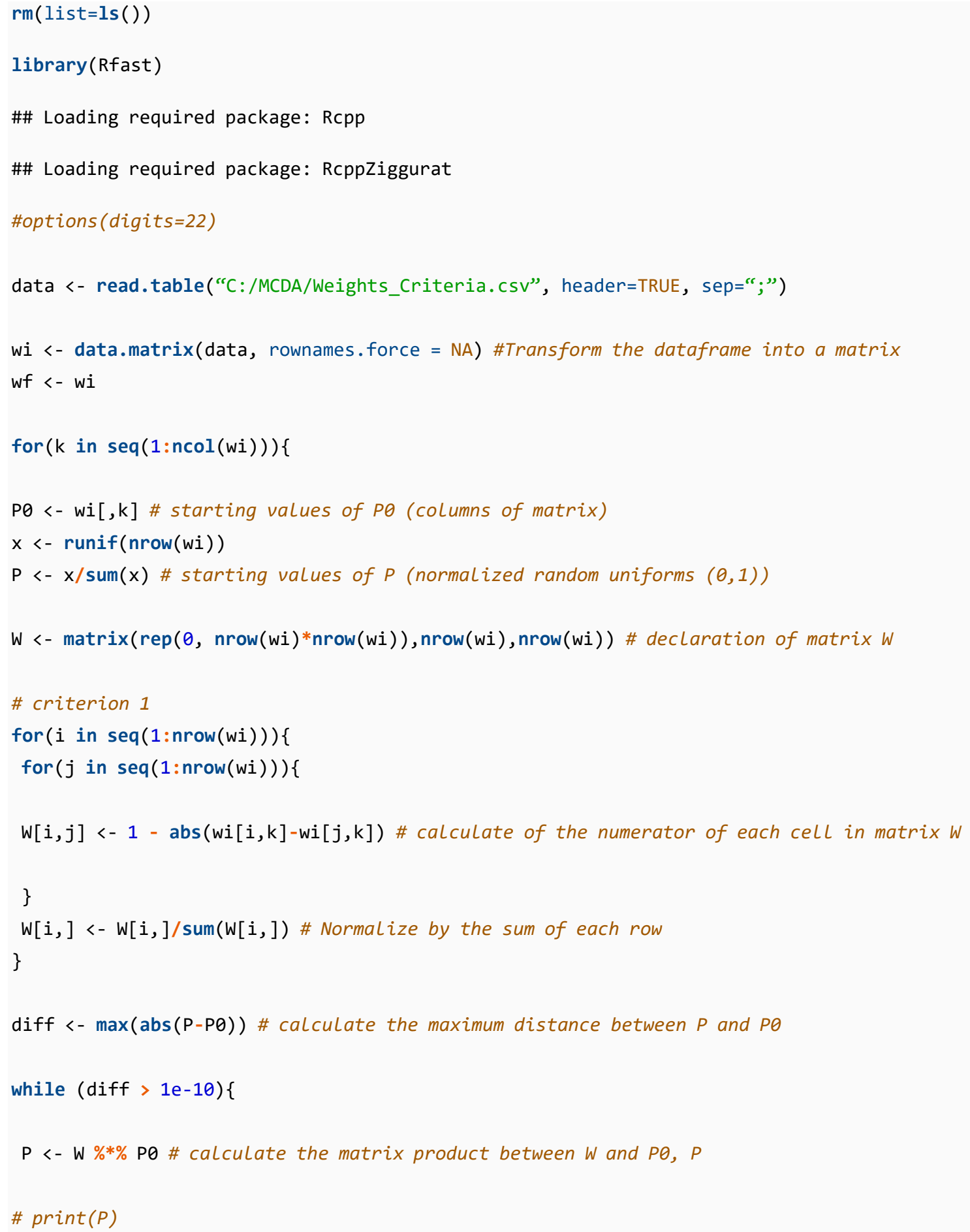




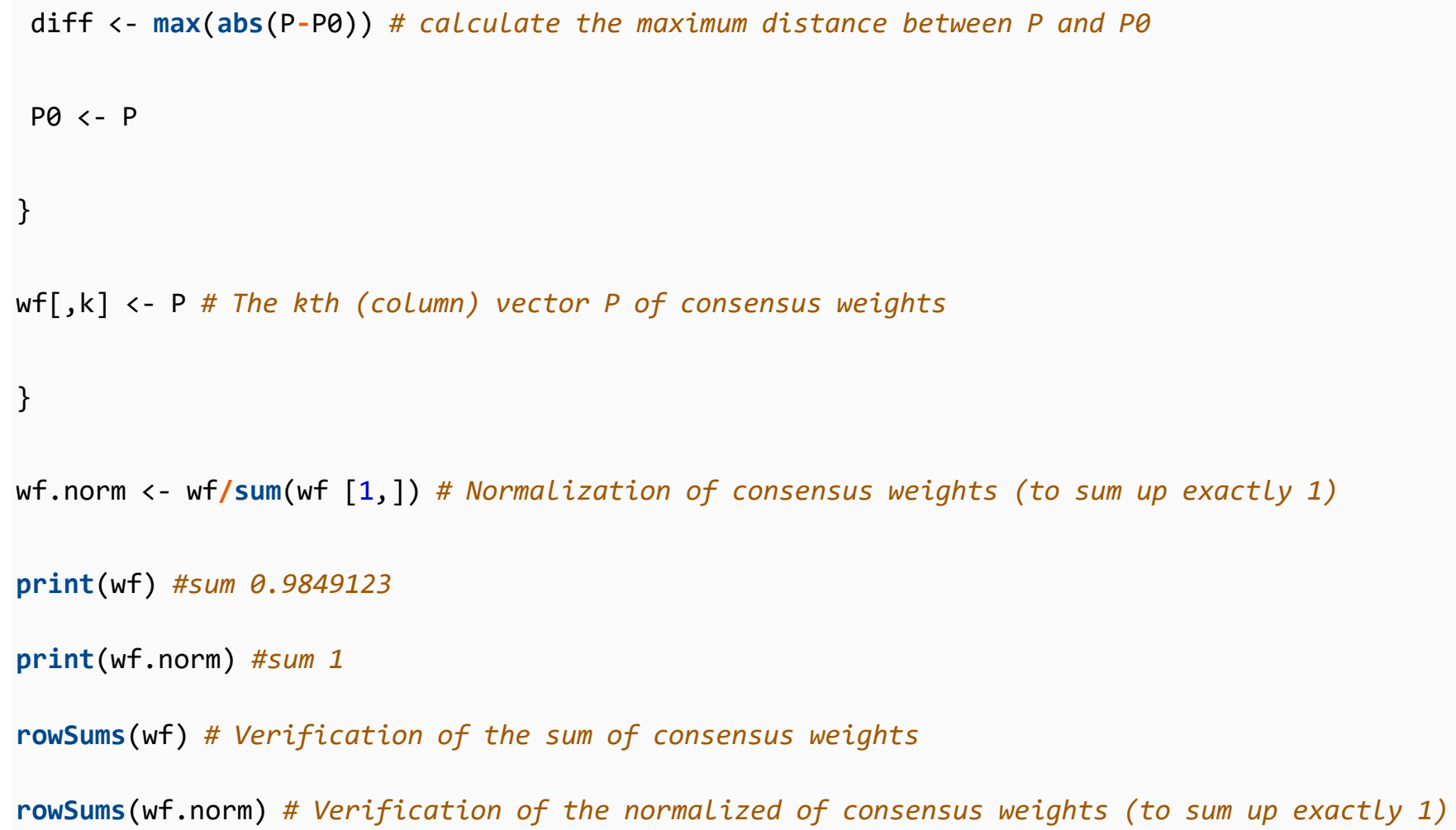

\section{References}

1. Diaz-Balteiro, L.; Romero, C. Making forestry decisions with multiple criteria: A review and an assessment. For. Ecol. Manag. 2008, 255, 3222-3241. [CrossRef]

2. Segura, M.; Ray, D.; Maroto, C. Decision support systems for forest management: A comparative analysis and assessment. Comput. Electron. Agric. 2014, 101, 55-67. [CrossRef]

3. Ortiz-Urbina, E.; González-Pachón, J.; Diaz-Balteiro, L. Decision-making in forestry: A review of the hybridisation of multiple criteria and group decision-making methods. Forests 2019, 10, 375. [CrossRef]

4. Belton, V.; Stewart, T.J. Multiple Criteria Decision Analysis: An Integrated Approach; Springer-Science+Business Media, B.V.: Berlin/Heidelberg, Germany, 2002; ISBN 0-7923-7505-x.

5. Valente, S.; Coelho, C.; Ribeiro, C. Forest Intervention Areas (ZIF): A New Approach for Non-Industrial Private Forest Management in Portugal. Silva Lusit. 2013, 21, 137-161.

6. $\quad$ Borges, J.G.; Marques, S.; Garcia-Gonzalo, J.; Rahman, A.U.; Bushenkov, V.; Sottomayor, M.; Carvalho, P.O.; Nordstrom, E.M.; Nordström, E.-M. A Multiple Criteria Approach for Negotiating Ecosystem Services Supply Targets and Forest Owners' Programs. For. Sci. 2017, 63, 49-61. [CrossRef]

7. ALTERFOR. Alternative Models and Robust Decision-Making for Future Forest Management (ALTERFOR). Available online: https: / / alterfor-project.eu/ (accessed on 7 December 2020).

8. Nordström, E.M.; Nieuwenhuis, M.; Başkent, E.Z.; Biber, P.; Black, K.; Borges, J.G.; Bugalho, M.N.; Corradini, G.; Corrigan, E.; Eriksson, L.O.; et al. Forest decision support systems for the analysis of ecosystem services provisioning at the landscape scale under global climate and market change scenarios. Eur. J. For. Res. 2019. [CrossRef]

9. Keeney, R.L.; Raiffa, H. Decisions with Multiple Objectives: Preferences and Value Trade-Offs; Cambridge University Press: Cambridge, UK, 1993. [CrossRef]

10. Marttunen, M.; Lienert, J.; Belton, V. Structuring problems for Multi-Criteria Decision Analysis in practice: A literature review of method combinations. Eur. J. Oper. Res. 2017, 263, 1-17. [CrossRef]

11. Murphy, P.; Solan, A.; Gibbon, J. Criterium Decision Plus. Version 3.05. Tutorial; InfoHarvest Inc.: Seattle, WA, USA, 2013.

12. Uhde, B.; Hahn, A.; Griess, V.C.; Knoke, T. Hybrid MCDA Methods to Integrate Multiple Ecosystem Services in Forest Management Planning: A Critical Review. Environ. Manag. 2015, 56, 373-388. [CrossRef] [PubMed]

13. Mendoza, G.A.; Martins, H. Multi-criteria decision analysis in natural resource management: A critical review of methods and new modelling paradigms. For. Ecol. Manag. 2006, 230, 1-22. [CrossRef]

14. Ananda, J.; Herath, G. A critical review of multi-criteria decision making methods with special reference to forest management and planning. Ecol. Econ. 2009, 68, 2535-2548. [CrossRef]

15. Corral, S.; Acosta, M. Social sensitivity analysis in conflictive environmental governance: A case of forest planning. Environ. Impact Assess. Rev. 2017, 65, 54-62. [CrossRef] 
16. Hujala, T.; Khadka, C.; Wolfslehner, B.; Vacik, H. Review. Supporting problem structuring with computer-based tools in participatory forest planning. For. Syst. 2013, 22, 270-281. [CrossRef]

17. Kangas, J.; Kangas, A. Multiple criteria decision support in forest management-The approach, methods applied, and experiences gained. For. Ecol. Manag. 2005, 207, 133-143. [CrossRef]

18. Maroto, C.; Segura, M.; Ginestar, C.; Uriol, J.; Segura, B. Sustainable forest management in a Mediterranean region: Social preferences. For. Syst. 2013, 22, 546-558. [CrossRef]

19. Kangas, A.; Laukkanen, S.; Kangas, J. Social choice theory and its applications in sustainable forest management-a review. For. Policy Econ. 2006, 9, 77-92. [CrossRef]

20. Schmoldt, D.L.; Peterson, D.L. Analytical group decision making in natural resources: Methodology and application. For. Sci. 2000, 46, 62-75.

21. Marques, M.; Oliveira, M.; Borges, J.G. An approach to assess actors' preferences and social learning to enhance participatory forest management planning. Trees For. People 2020, 2, 100026. [CrossRef]

22. Buchy, M.; Hoverman, S. Understanding public participation in forest planning: A review. For. Policy Econ. 2000, 1, 15-25. [CrossRef]

23. Maroto, M.S. Assessment of Ecosystem Services based on Multiple Criteria and Group Decision Making; Universitat Politècnica de València: Valéncia, Spain, 2015.

24. de Sousa Xavier, A.M.; Costa Freitas, M.D.B.; de Sousa Fragoso, R.M. Management of Mediterranean forests-A compromise programming approach considering different stakeholders and different objectives. For. Policy Econ. 2015, 57, 38-46. [CrossRef]

25. Eden, C.; Ackermann, F. Cognitive mapping expert views for policy analysis in the public sector. Eur. J. Oper. Res. 2004, 152, 615-630. [CrossRef]

26. Saaty, T.L. Hierarchies and priorities: A first look. In The Analytic Hierarchy Process. Planning, Priority Setting, Resource Allocation; McGraw-Hill International Book Company: New York, NY, USA, 1980; pp. 3-34.

27. Saaty, T.L. Decision making with the analytic hierarchy process. Int. J. Serv. Sci. 2008, 1, 83-98. [CrossRef]

28. Goodwin, P.; Wright, G. Decisions involving multiple objectives: SMART. In Decision Analysis for Management Judgment; John Wiley \& Sons, Ltd.: West Sussex, UK, 2004; pp. 27-70.

29. Linstone, H.A.; Turoff, M. The Delphi Method-Techniques and Applications; Advanced Book Program; Addison-Wesley Publishing Company: Reading, MA, USA, 2002; ISBN 0201042940.

30. Rowe, G.; Wright, G. The Delphi technique: Past, present, and future prospects—Introduction to the special issue. Technol. Forecast. Soc. Chang. 2011, 78, 1487-1490. [CrossRef]

31. von der Gracht, H.A. Consensus measurement in Delphi studies. Review and implications for future quality assurance. Technol. Forecast. Soc. Chang. 2012, 79, 1525-1536. [CrossRef]

32. Deliverables in Work Package 4. Available online: https: / / alterfor-project.eu/wp4.html (accessed on 7 December 2020).

33. Marques, M.; Juerges, N.; Borges, J.G. Appraisal framework for actor interest and power analysis in forest management-Insights from Northern Portugal. For. Policy Econ. 2020, 111, 14. [CrossRef]

34. Franco, L.A.; Montibeller, G. Problem Structuring for Multicriteria Decision Analysis Interventions. In Wiley Encyclopedia of Operations Research and Management Science; Cochran, J.J., Cox, L.A., Keskinocak, P., Kharoufeh, J.P., Smith, J.C., Eds.; John Wiley \& Sons, Inc.: Hoboken, NJ, USA, 2010; pp. 1-14. [CrossRef]

35. Reynolds, K.M.; Hessburg, P.F.; Bourgeron, P.S. Making Transparent Environmental Management Decisions. Applications of the Ecosystem Management Decision Support System; Springer: Berlin/Heidelberg, Germany, 2014; ISBN 978-3-642-31999-0.

36. von Winterfeldt, D.; Edwards, W. Decision Analysis and Behavioral Research; Cambridge University Press: Cambridge, UK, 1986.

37. Lakicevic, M.D.; Reynolds, K.M.; Srdjevic, B.M. Assessing landscape plans with abbreviated pair-wise comparisons in the AHP (Analitic Hierarchy Process). Zb. Matice Srp. Prir. Nauk. 2019, 253, 183-194. [CrossRef]

38. Strager, M.P.; Rosenberger, R.S. Incorporating stakeholder preferences for land conservation: Weights and measures in spatial MCA. Ecol. Econ. 2006, 58, 79-92. [CrossRef]

39. Regan, H.M.; Colyvan, M.; Markovchick-Nicholls, L. A formal model for consensus and negotiation in environmental management. J. Environ. Manag. 2006, 80, 167-176. [CrossRef] [PubMed]

40. Nordström, E.M.; Eriksson, L.O.; Öhman, K. Integrating multiple criteria decision analysis in participatory forest planning: Experience from a case study in northern Sweden. For. Policy Econ. 2010, 12, 562-574. [CrossRef]

41. Gregory, R.; Failing, L.; Harstone, M.; Long, G.; McDaniels, T.; Ohlson, D.; John, A. Structured Decision Making. A practical Guide to Environmental Management Choices; Wiley-Blackwell: West Sussex, UK, 2012; ISBN 9781444333411.

42. Nunes, L.J.R.; Meireles, C.I.R.; Gomes, C.J.P.; Ribeiro, N.M.C.A. The Evolution of Climate Changes in Portugal: Determination of Trend Series and Its Impact on. Climate 2019, 7, 78. [CrossRef]

43. Fontana, V.; Radtke, A.; Bossi Fedrigotti, V.; Tappeiner, U.; Tasser, E.; Zerbe, S.; Buchholz, T. Comparing land-use alternatives: Using the ecosystem services concept to define a multi-criteria decision analysis. Ecol. Econ. 2013, 93, 128-136. [CrossRef]

44. Segura, M.; Maroto, C.; Belton, V.; Ginestar, C. A new collaborative methodology for assessment and management of ecosystem services. Forests 2015, 6, 1696-1720. [CrossRef]

45. Phillips, L.D. Decision conferencing. In Advances in Decision Analysis: From Foundations to Applications; Edwards, W., Miles, R.F., von Winterfeldt, D., Eds.; Cambridge University Press: Cambridge, UK, 2007; pp. 375-399. ISBN 9780511611308. 